\title{
内蒙古达茂旗满都拉地区早二叠世基性岩的 年代学、地球化学及其地质意义
}

\author{
晨辰，张志诚，郭召杰，李建锋，冯志硕，汤文豪 \\ 北京大学造山带与地壳演化教育部重点实验室, 北京大学地球与空间科学学院, 北京 100871 \\ * 联系人, E-mail: zczhang@pku.edu.cn; zczhang_163@163.com
}

收稿日期: 2010-10-11; 接受日期: 2011-03-24

中国地质调查局项目(编号：1212010050503)、国家自然科学基金项目(批准号：40672146)和国家重点基础研究发展计划项目(编号： 2007CB411305)资助

\begin{abstract}
摘要 内蒙古达茂旗满都拉地区胡吉尔特-查干哈达庙一带出露一套基性岩系, 主 要为基性喷出岩，其间出露条带状超基性岩，同时在基性熔岩的东部伴生有一系列 中基性侵入岩体. 其中辉长岩和玄武岩样品的锆石 SHRIMP U-Pb 年龄分别为 (278.5 \pm 3.0$) \mathrm{Ma}(\mathrm{MSWD}=0.66)$ 和(273.7 \pm 1.0$) \mathrm{Ma}(\mathrm{MSWD}=0.36)$ ，表明这套基性岩形成 于早二叠世. 地球化学分析表明, 满都拉地区二叠纪基性岩稀土元素丰度较低, 具有 LREE 轻度亏损、HREE 轻度富集的与 N-MORB 相似的稀土元素分布特征; 基性熔 岩具有高的 $\left({ }^{143} \mathrm{Nd} /{ }^{144} \mathrm{Nd}\right)_{\mathrm{i}}$ 值 $(0.51262 \sim 0.51270)$ 、较高的正 $\varepsilon_{\mathrm{Nd}}(t)$ 值(3.4 8.0) 和 $\mathrm{Mg}^{\#}$ 值 (49 54), 指示了其来源是亏损的软流圈地幔; 相对富集 $\mathrm{Rb}, \mathrm{Ba}$ 和 $\mathrm{Sr}$ 等大离子亲石元 素(LILE), 亏损高场强元素(HFSE), $\mathrm{Nb}$ 和 $\mathrm{Ta}$ 具有明显的负异常, $\mathrm{P}$ 和 $\mathrm{Ti}$ 有微弱的负 异常, 较高 $\left({ }^{87} \mathrm{Sr} /{ }^{86} \mathrm{Sr}\right)_{\mathrm{i}}$ 值 $(0.70490 \sim 0.70537)$ 、较低 $\left({ }^{206} \mathrm{~Pb} /{ }^{204} \mathrm{~Pb}\right)_{\mathrm{i}}$ 值 $(17.39 \sim 17.93)$ 等富集 地幔或者岛弧火山岩的地球化学信息共同显示出源区的复杂性. 结合 $\mathrm{La} / \mathrm{Nb}$ 比值、 $\mathrm{Nd}-\mathrm{Sr}$ 同位素初始比值图解、 $\mathrm{Pb}$ 同位素初始比值图解、 $\mathrm{La} / \mathrm{Ba}-\mathrm{La} / \mathrm{Nb}$ 图解等认为岩浆 源区可能受到了与俯冲消减有关的混染和交代作用。同时样品中较大的同位素组成 及元素比值变化范围说明岩浆在上升侵位过程中可能受到了不同程度的陆壳/弧物质 的混染. 综合研究区基性岩地球化学特征和前人资料表明, 满都拉地区的二叠纪基 性岩形成于强烈裂谷作用背景, 当时区域上可能存在类似于现今红海的有限洋盆.

关键词

满都拉

锆石 SHRIMP U-Pb 年龄

二叠纪

地球化学分析

拉张作用
\end{abstract}

中亚造山带为一个巨大的增生型造山带, 是全 球显生宙增生最强烈的地区之一 ${ }^{[1 ~ 4]}$. 中亚造山带的 演化历史从 $1.0 \mathrm{Ga}$ 开始 ${ }^{[3,4]}$, 经历了多期次大洋板片 的俯冲碰撞过程 ${ }^{[5]}$, 一直延续到古亚洲洋闭合时结束.
华北板块与西伯利亚板块碰撞形成的大兴安岭-内蒙 古造山带 ${ }^{66}$, 是中亚造山带的东南部分, 长期以来一 直是研究华北北缘构造演化历史的关键地区. 目前, 对于最终碰撞、缝合的位置大多数地质学家已取得共

英文引用格式: Chen C, Zhang Z C, Guo Z J, et al. Geochronology, geochemistry, and its geological significance of the Permian Mandula mafic rocks in Damaoqi, Inner Mongolia. Sci China Earth Sci, 2012, 55: 39-52, doi: 10.1007/s11430-011-4277-z 
识, 即位于索伦缝合带 ${ }^{[7 ~ 13]}$. 但是, 目前对于西伯利 亚板块与华北板块碰撞的时限问题存在较大争议. 一些学者认为最后缝合发生在二叠到早三叠世 ${ }^{[10 ~ 21]}$, 如 Xiao 等 ${ }^{[10]}$ 通过对大兴安岭-内蒙古造山带的增生 楔和蛇绿岩的研究认为古亚洲洋在晚二叠到早三叠 世最终闭合于索伦缝合带; Chen 等 ${ }^{[16]}$ 对哈拉图碰撞 花岗岩及与俯冲作用相关岩体定年得出碰撞应发生 于 310 230 Ma 之间; Zhang 等 ${ }^{[19]}$ 在华北克拉通北缘 发现了一条晚古生代形成的陆弧岩浆带, 进而推断 两板块碰撞应晚于 $290 \mathrm{Ma}$; 最近, Miao 等 ${ }^{[20]}$ 对贺根 山蛇绿岩和相关长英质侵入岩的研究结果显示古亚 洲洋的闭合应发生在 298 244 Ma 之间. 另外一些学 者则认为, 碰撞发生在泥盆纪或者晚泥盆到早石炭 $世^{[7,8,22 ~ 29]}$. Tang ${ }^{[7]}$ 认为西伯利亚板块与华北板块的碰 撞发生在泥盆纪之前, 依据是缝合带的岩石组合和 沉积相分析; 邵济安 ${ }^{[8]}$ 依据晚古生代地层的沉积相、 蛇绿岩的特征, 认为俯冲作用在石炭纪已经完成; Zhang 等 ${ }^{[24]}$ 对锡林浩特二叠纪双峰式火山岩的成因 研究认为自 $280 \mathrm{Ma}$ 以来区域上已经进入碰撞后伸展 阶段, 与 Shi 等 ${ }^{[25]}$ 在此区对 $\mathrm{A}$ 型花岗岩研究得出的结 论相同; 罗红玲等 ${ }^{[26]}$ 通过对乌梁斯太 A 型花岗岩研 究也显示出华北板块北缘在早二叠晚期已经进入后 碰撞阶段; 最近在东乌珠穆沈旗发现的含华夏植物 群的中、下二叠统, 再次为古亚洲洋在早二叠世之前 已经闭合的观点提供了新证据 ${ }^{[27]}$.

达茂旗北部满都拉地区处于索伦缝合带的西段, 出露大量晚古生代火山岩, 但对其准确定年数据较 少, 因此对晚古生代的构造演化背景仍存在争议. 陶 继雄等 ${ }^{[30]}$ 通过对本区的火山岩系和深成侵入岩的岩 石地球化学进行研究, 认为其具有大洋岛弧岩浆岩 的特点, 二叠纪早期本区依然存在大洋板块活动; 苏 新旭等 ${ }^{[31]}$ 也在该区发现了一套二叠纪早期大洋岛弧 岩浆岩, 因此认为古亚洲洋在本区的缝合时间至少 为早二叠世之后. 尚庆华 ${ }^{[18]} 、$ 王惠等 ${ }^{[32]}$ 相继在满都拉 地区发现二叠纪的放射虫化石, 认为该时期华北板 块与西伯利亚板块间仍存在深水盆地. 本文对满都 拉南部区域出露的基性火山岩进行精确锆石 SHRIMP U-Pb 年龄测定, 并结合其地球化学特征分 析, 系统研究满都拉地区在晚古生代的火山活动特 征及大地构造环境, 为进一步探讨华北板块与西伯 利亚板块拼合的时间以及碰撞演化历史提供新的依 据.

\section{1 地质背景和岩体特征}

满都拉地区位于达茂旗北部，构造部位处于西 伯利亚板块和华北板块会聚地带 ${ }^{[9]}$, 是研究古亚洲洋 俯冲、碰撞造山的重要地区. 研究区出露的二叠纪基 性岩系位于满都拉南约 $15 \mathrm{~km}$ 的胡吉尔特-查干哈达 庙一带(图 1), 以深灰或灰绿色玄武岩为主, 总体呈 东西向延伸, 长达约 $40 \mathrm{~km}$. 岩石组合特征为: 下部 主要为灰-灰绿-灰黑色块状玄武岩; 中部为深灰绿 色、灰紫色枕状、气孔杏仁状细碧岩; 上部深灰绿、 灰黑色气孔杏仁状、块状玄武岩. 岩性纵、横向变化 较大, 厚度 $>2130 \mathrm{~m}^{[31]}$. 在基性岩系的东部伴生一 系列由辉长岩、角闪辉长岩、闪长岩、石英闪长岩、 二长花岗岩、斜长花岗岩等构成的深成侵入岩序列, 该序列呈北东向展布. 侵入岩由一系列独立的小岩 株组成, 基岩出露较差, 岩石均为碎块状, 但较新鲜, 与玄武岩围岩界线多处被覆盖, 接触界面特征较难 观察 ${ }^{[30]}$. 研究区域可见超基性岩带出露, 多呈条带状 产于玄武岩中, 总体近东西向延伸.

二叠纪基性火山岩的北侧自西向东分别被白严 系上统不整合覆盖、与石炭系上统阿木山组呈断层接 触、与二叠系下统包格特组断层接触; 南侧除行格宝 木太地区的火山岩与石炭系本巴图组为断层接触外, 其他区域均与中新生代地层呈不整合接触. 阿木山 组上段为砂岩、长石石英砂岩夹砂质板岩, 下段自下 而上岩性依次为: 凝灰质砂岩、粉砂岩; 硬砂质长石 砂岩夹粉砂岩、凝灰岩; 生物碎屑灰岩夹凝灰岩. 阿 木山组向上与二叠系下统包特格组地层呈不整合接 触. 本区出露的包特格组下部岩性为砂砾岩、砾岩夹 英安岩、灰岩; 中部为厚层状火山质砾岩夹灰黑色火 山灰凝灰岩; 上部为中粗粒硬砂岩夹砂砾岩、凝灰 岩、灰岩.

研究样品分别采自胡吉尔特西北侧的玄武岩和 查干哈达庙南侧的辉长岩、辉绿岩(图 1). 玄武岩以 灰色、灰绿色为主, 发育块状构造. 薄片研究表明, 玄武岩蚀变程度较低(图 2(a), (b)), 具斑状结构, 斑晶 含量约为 $15 \%$, 主要为辉石、斜长石. 基质为间粒间隐结构, 长柱状的斜长石杂乱分布并构成交错的 格架, 在间隙中充填有他形的辉石颗粒或隐晶质. 辉长、辉绿岩以暗绿色为主, 发育块状构造. 显微镜 下观察样品较新鲜(图 2(c), (d)), 未发生变质, 具辉 长、辉绿结构. 


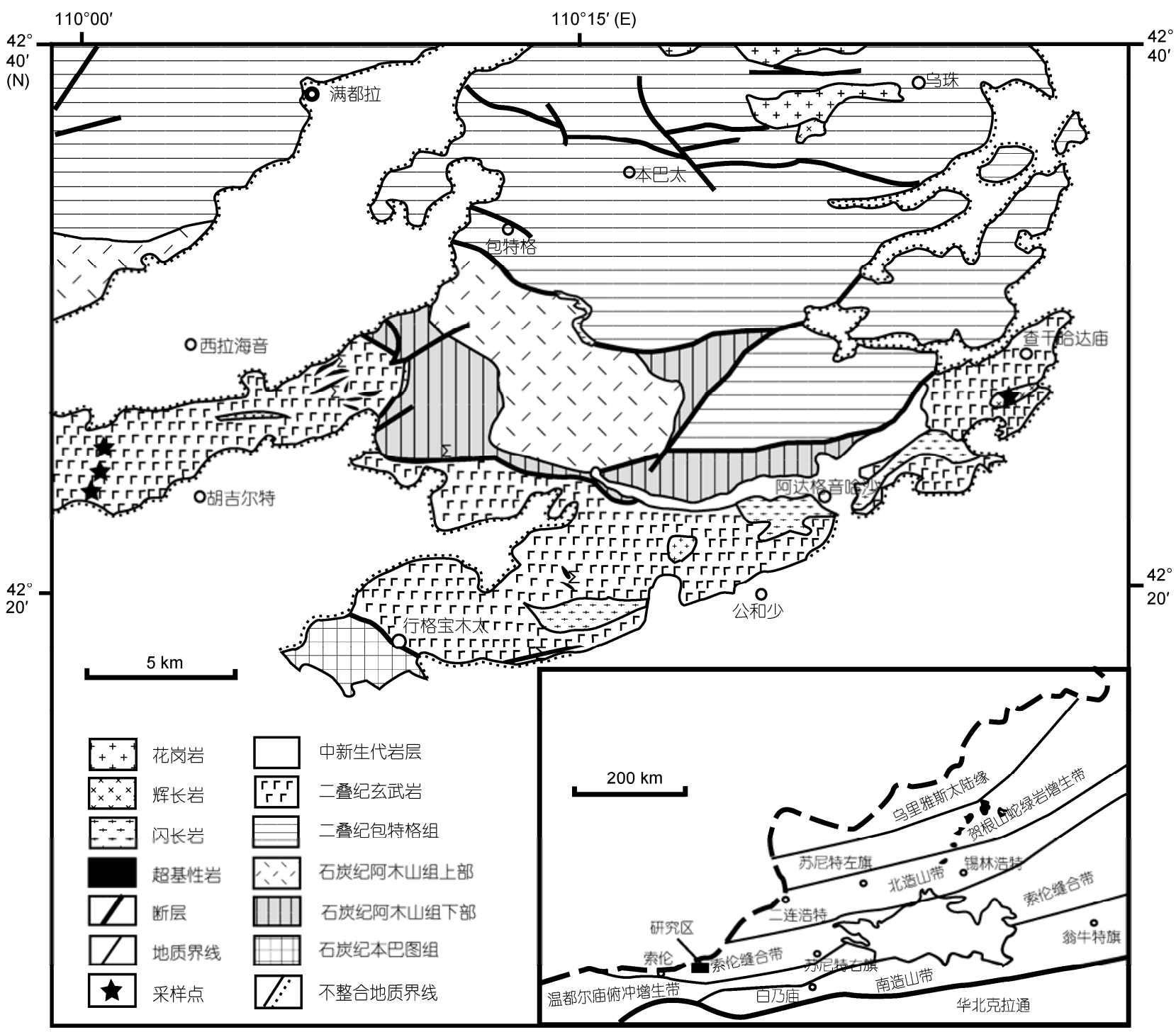

图 1 内蒙古满都拉地区地质简图 据脚注 1)及文献[33]修改

\section{2 锆石 SHRIMP U-Pb 定年}

\section{1 分析方法}

从辉长岩-辉绿岩和玄武岩样品中各选出一个样 品进行了 SHRIMP U-Pb 年龄测定. 样品的锆石分选 在廊坊诚信地质技术服务公司进行. 锆石按常规方 法分选, 先将样品破碎至 $100 \mu \mathrm{m}$ 左右, 先用磁法和 重液分选, 最后在双目镜下挑纯. 将锆石与数粒标准 锆石 TEMORA 置于环氧树脂中, 然后磨至约 $1 / 2$,
使锆石内部新鲜部分暴露，最后制成厚 5 6 mm、直 径约 $35 \mathrm{~mm}$ 的圆形靶, 并抛光、镀金, 用于阴极发光 及随后的 SHRIMP U-Pb 分析. 测试前在北京大学 造山带与地壳演化实验室和北京大学显微镜室拍摄 了可见光和阴极发光(CL) 照片(图 3).

锆石 $\mathrm{U}-\mathrm{Pb}$ 年龄数据是在中国地质科学院地质研 究所北京离子探针中心的网络虚拟实验室, 通过位 于澳大利亚 Curtin 理工大学(Curtin University of Technology) SHRIMP II 仪器的 SHRIMP远程共享控

1) 内蒙古自治区地质局. 中华人民共和国区域地质报告查干哈达幅 (1:20 万). 1980 

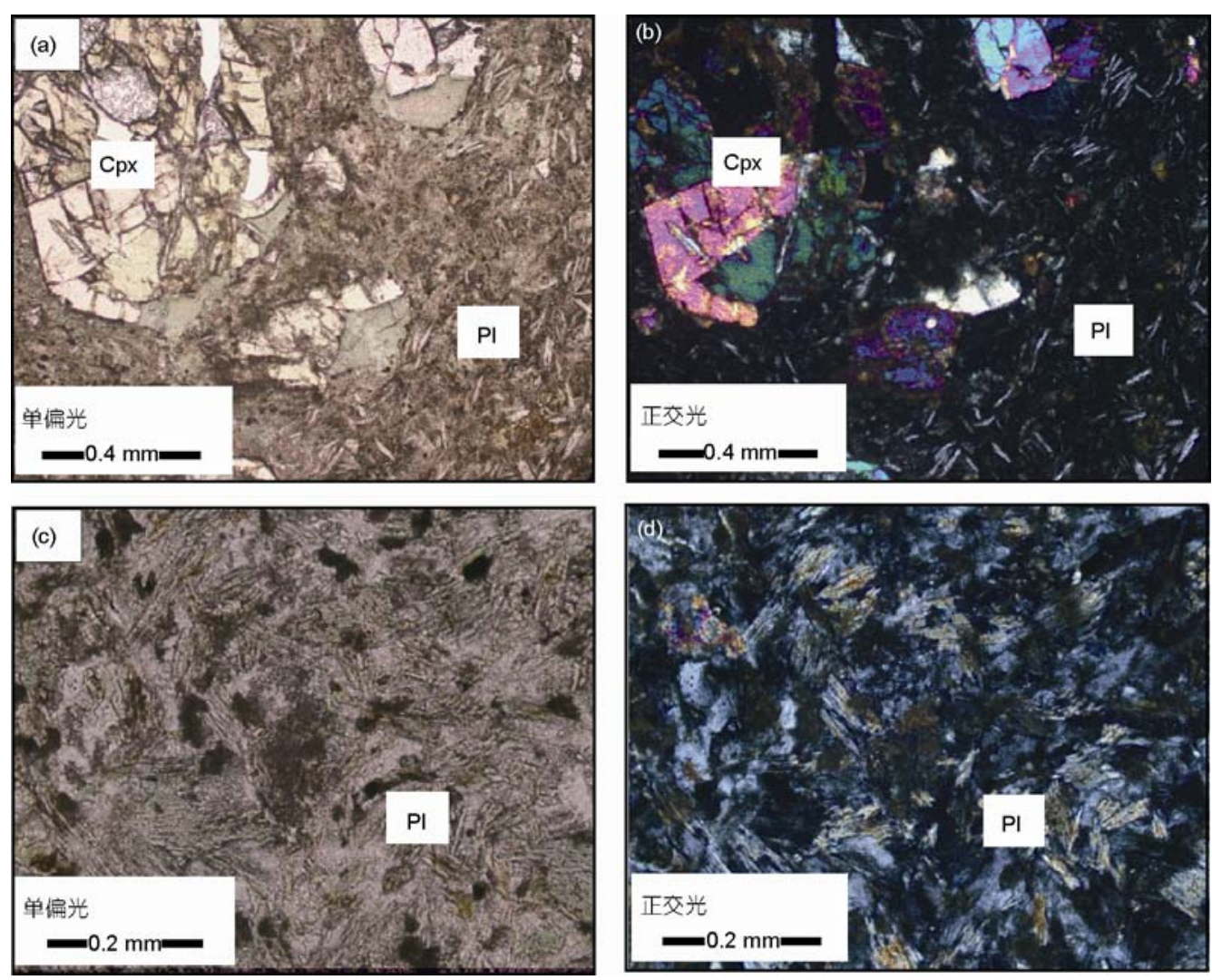

图 2 满都拉基性岩显微照片

PI-斜长石; Cpx-单斜辉石. (a), (b) 玄武岩样品斑状结构; (c), (d) 辉绿岩样品辉绿结构

制系统(SHRIMP Remote Operation System, SROS)获 得. 分析流程和方法见文献[34, 35]. 用 TEMORA1 (417 Ma) 进行元素间的分馏校正, 使用标准样品 $\mathrm{M} 257^{[36]}$ 标定所测样品的 $\mathrm{U}, \mathrm{Th}$ 和 $\mathrm{Pb}$ 含量. 以锆石阴 极发光图像为依据, 选择不同部位进行测试. 测试过 程中每隔 3 4 个样品点插入一个 TEMORA 测定值. 表 1 列出的 SHRIMP 分析数据是每个锆石点连续 5 次分析的平均值, 误差为 $1 \sigma,{ }^{206} \mathrm{~Pb} /{ }^{238} \mathrm{U}$ 加权平均年 龄值计算使用 ISOPLOT 程序 ${ }^{[37]}$, 其置信度为 $95 \%$. 在整个数据处理过程中, 年龄计算使用的衰变常数 见文献[38]. 最后根据表 1 中的测试数据, 利用 ISOPLOT 程序绘制年龄谐和图(图 4).

\section{2 锆石特征及定年结果}

从辉长岩样品 NM08-188 分选出的锆石颗粒大 部分呈长柱状, 长宽比 $2: 1$, 个别为 $3: 1$, 晶型为半自 形-自形, 晶面整洁光滑. 在阴极发光照片上, 未见具 有明显核部的颗粒, 大多数锆石都具有清晰的较宽
的结晶环带, 表明它们是岩浆结晶形成的. 11 颗锆石 的离子探针测试结果见表 1 . 锆石的 $\mathrm{Th} / \mathrm{U}$ 值变化范 围介于 $0.21 \sim 0.56$. 样品的 11 颗锆石的定年数据点大 部分落在谐和线上, 个别数据点稍有偏离. 所有锆石 颗粒的年龄测定值均很稳定, 集中分布于 $280 \mathrm{Ma}$ 附 近, 其加权平均值为 $(278.5 \pm 3.0) \mathrm{Ma}$, 代表了锆石的 结晶年龄.

从玄武岩样品 NM08-73 分选出的锆石颗粒不规 则, 呈等粒状、椭圆粒状、长柱状等, 晶型为半自形自形, 晶面整洁光滑. 在阴极发光照片上, 大多数的 锆石都显示出较清晰的环带结构, 同样表明它们是 岩浆结晶形成的. 有部分锆石具有明显的核部, 且生 长环带明显切割内部的生长环带, 如 2, 4 和 8 号等, 可能反映了他们比较复杂的成因. 12 颗锆石的离子探 针测试结果见表 1. 其中有 5 个分析点 $(2,5,10 \sim 12$ 号 锆石)的普通铅含量大于 $1 \%$, 锆石 CL 图像分析表明 可能由于样品存在裂缝或包体所致, 会对测试的精 度产生一定影响. 除去颗粒 NM08-73-3, NM08-73-8 

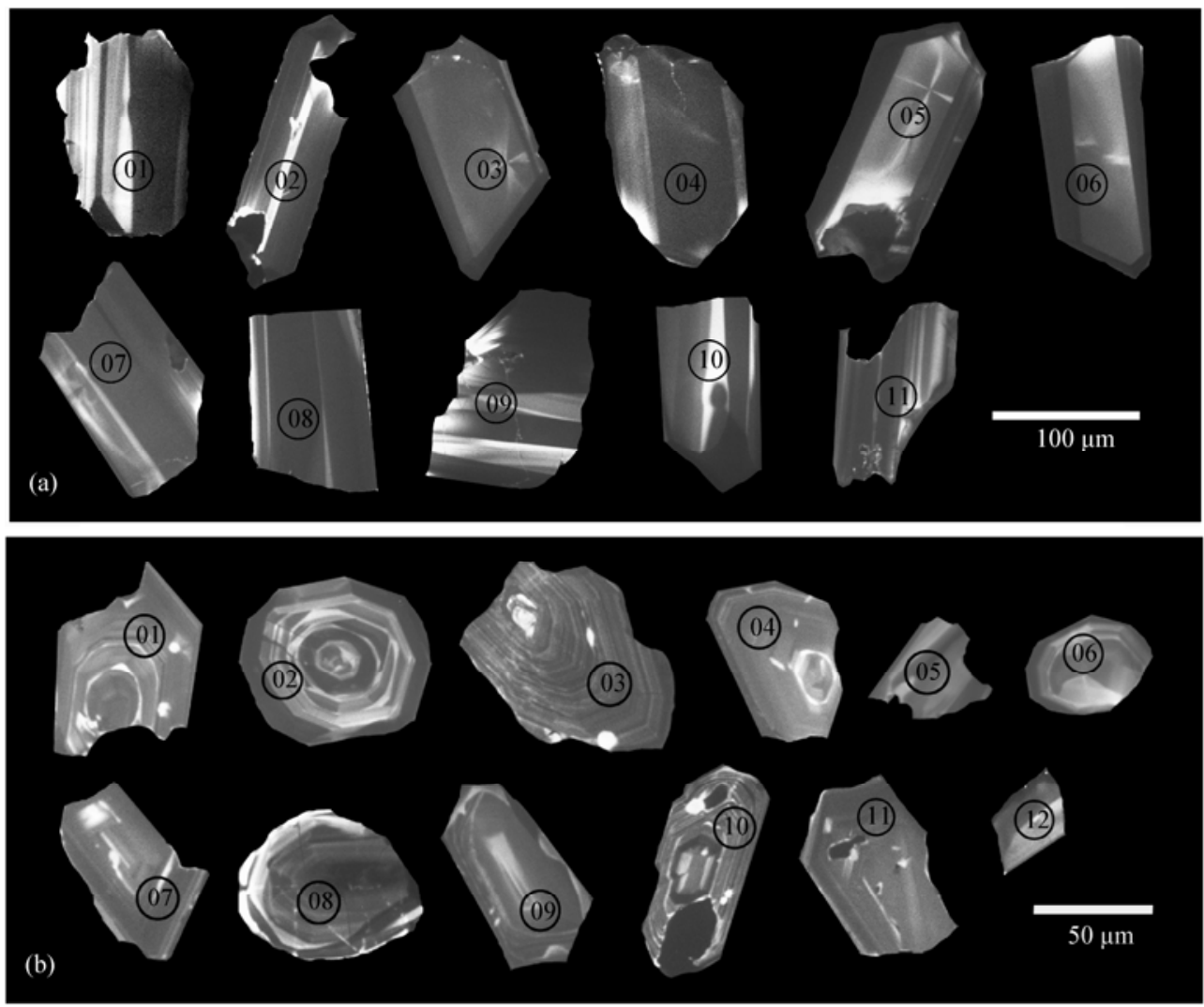

图 3 NM08-188 辉长岩锆石阴极发光(CL)图像(a)及 NM08-73 玄武岩锆石阴极发光(CL)图像(b)
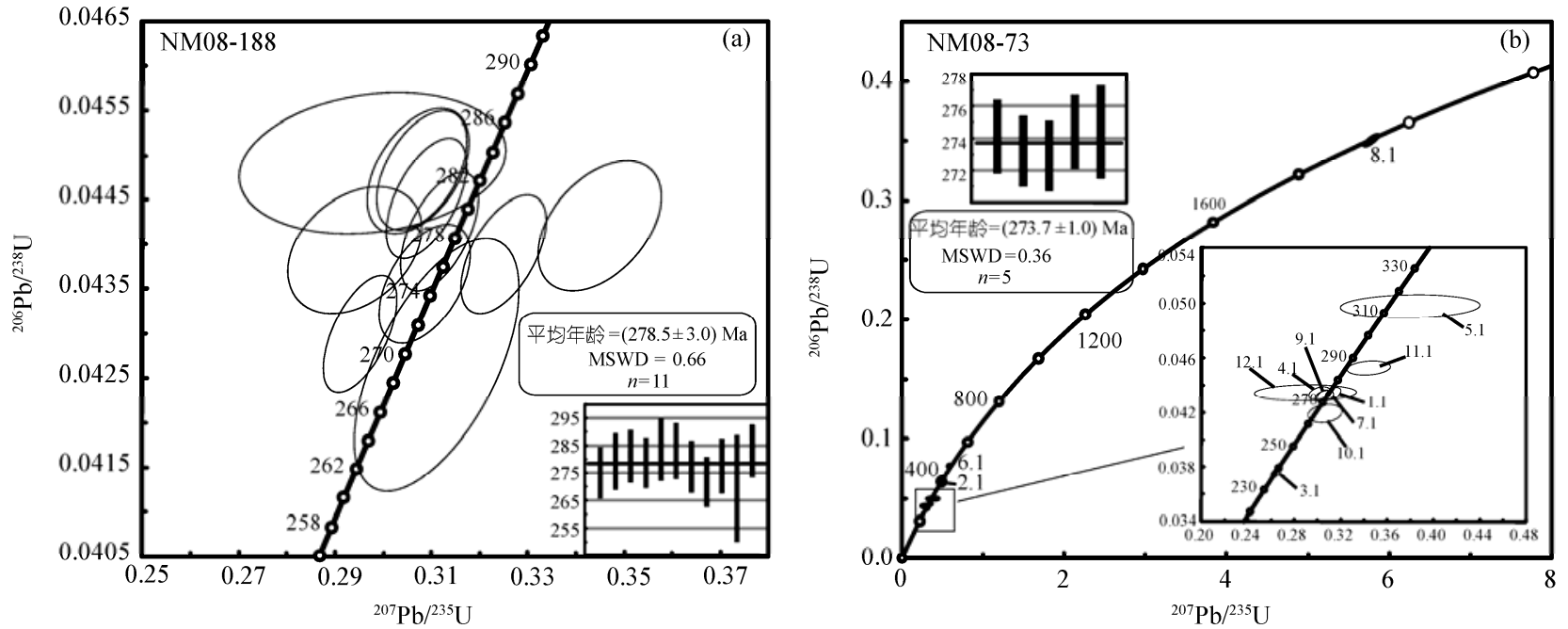

图 4 NM08-188 辉长岩(a)和 NM08-73 玄武岩(b)锆石 SHRIMP U-Pb 年龄协和图

外, 锆石的 $\mathrm{Th} / \mathrm{U}$ 值变化范围介于 $0.48 \sim 0.87$, 平均值 为 0.58 , 表现出了岩浆锆石的 $\mathrm{Th}, \mathrm{U}$ 地球化学特征. 2 号、6 号和 8 号测点的 U-Pb 年龄分别为 394, 481 和 $1940 \mathrm{Ma}$, 大于测试点集中的 $275 \mathrm{Ma}$ 年龄值, 也就是
玄武岩的形成年龄，它们可能为岩浆上侵过程中从 围岩或者从源区中捕获的继承性锆石. 11 号锆石的数 据点落在谐和线下方, 反映了可能存在部分的 $U$ 或 者 $\mathrm{Pb}$ 丢失. 5 号锆石的年龄数据 $(313 \mathrm{Ma})$ 落在谐和 
表 1 满都拉基性岩锆石 SHRIMP U-Pb 分析结果

\begin{tabular}{|c|c|c|c|c|c|c|c|c|c|c|c|c|c|}
\hline \multirow[b]{2}{*}{ 测点 } & \multirow[b]{2}{*}{$\begin{array}{l}{ }^{206} \mathrm{~Pb}_{\mathrm{c}} \\
(\mathrm{ppm})^{\mathrm{a})}\end{array}$} & \multirow[b]{2}{*}{$\mathrm{U}(\mathrm{ppm})$} & \multirow[b]{2}{*}{$\operatorname{Th}(\mathrm{ppm})$} & \multirow[b]{2}{*}{${ }^{232} \mathrm{Th} /{ }^{238} \mathrm{U}$} & \multirow[b]{2}{*}{$\begin{array}{l}{ }^{206} \mathrm{~Pb}^{*} \\
(\mathrm{ppm})^{\mathrm{a})}\end{array}$} & \multicolumn{3}{|c|}{ 年龄 $\pm 1 \sigma(\mathrm{Ma})$} & \multicolumn{4}{|c|}{ 比值 } & \multirow[b]{2}{*}{$\begin{array}{l}\text { 误差相 } \\
\text { 关系数 }\end{array}$} \\
\hline & & & & & & $\begin{array}{l}{ }^{206} \mathrm{~Pb} / \\
{ }^{238} \mathrm{U}^{\mathrm{b})}\end{array}$ & $\begin{array}{l}{ }^{206} \mathrm{~Pb} / \\
{ }^{238} \mathrm{U}^{\mathrm{c})}\end{array}$ & $\begin{array}{l}{ }^{206} \mathrm{~Pb} / \\
{ }^{238} \mathrm{U}^{\mathrm{d})}\end{array}$ & $\begin{array}{l}{ }^{207} \mathrm{~Pb}^{*} / \\
{ }^{235} \mathrm{U}^{\mathrm{b})}\end{array}$ & $\pm \%$ & $\begin{array}{l}{ }^{206} \mathrm{~Pb}^{*} / \\
{ }^{238} \mathrm{U}^{\mathrm{b})}\end{array}$ & $\pm \%$ & \\
\hline NM08-188-1 & 0.14 & 624 & 256 & 0.42 & 23.4 & $\begin{array}{c}275.1 \\
\pm 3.4\end{array}$ & $\begin{array}{c}275.4 \\
\pm 3.4\end{array}$ & $\begin{array}{c}275.9 \\
\pm 3.6\end{array}$ & 0.3215 & 1.8 & 0.04372 & 1.2 & 0.696 \\
\hline NM08-188-2 & - & 251 & 80 & 0.33 & 9.5 & $\begin{array}{c}279.2 \\
\pm 3.7\end{array}$ & $\begin{array}{c}277.6 \\
\pm 3.7\end{array}$ & $\begin{array}{c}278.4 \\
\pm 3.9\end{array}$ & 0.3286 & 2.5 & 0.04413 & 1.4 & 0.532 \\
\hline NM08-188-3 & - & 466 & 125 & 0.28 & 17.8 & $\begin{array}{c}281.1 \\
\pm 3.4\end{array}$ & $\begin{array}{c}281.7 \\
\pm 3.5\end{array}$ & $\begin{array}{c}281.0 \\
\pm 3.6\end{array}$ & 0.3056 & 2.0 & 0.04455 & 1.2 & 0.621 \\
\hline NM08-188-4 & 0.07 & 624 & 216 & 0.36 & 23.7 & $\begin{array}{c}278.7 \\
\pm 3.3\end{array}$ & $\begin{array}{c}279.0 \\
\pm 3.4\end{array}$ & $\begin{array}{c}279.1 \\
\pm 3.5\end{array}$ & 0.3180 & 1.8 & 0.04425 & 1.2 & 0.676 \\
\hline NM08-188-5 & 0.32 & 216 & 45 & 0.22 & 8.4 & $\begin{array}{c}283.5 \\
\pm 4.0\end{array}$ & $\begin{array}{c}284.9 \\
\pm 3.9\end{array}$ & $\begin{array}{c}284.5 \\
\pm 3.9\end{array}$ & 0.3167 & 2.6 & 0.04512 & 1.4 & 0.518 \\
\hline NM08-188-6 & 0.39 & 374 & 105 & 0.29 & 14.5 & $\begin{array}{c}283.0 \\
\pm 3.6\end{array}$ & $\begin{array}{c}283.8 \\
\pm 3.6\end{array}$ & $\begin{array}{c}283.9 \\
\pm 3.8\end{array}$ & 0.3243 & 2.2 & 0.04503 & 1.3 & 0.593 \\
\hline NM08-188-7 & - & 544 & 245 & 0.46 & 20.5 & $\begin{array}{c}277.2 \\
\pm 3.4\end{array}$ & $\begin{array}{c}276.6 \\
\pm 3.4\end{array}$ & $\begin{array}{c}277.3 \\
\pm 3.6\end{array}$ & 0.3264 & 1.9 & 0.04396 & 1.2 & 0.660 \\
\hline NM08-188-8 & 0.27 & 509 & 239 & 0.49 & 18.9 & $\begin{array}{c}271.7 \\
\pm 3.3\end{array}$ & $\begin{array}{c}272.4 \\
\pm 3.3\end{array}$ & $\begin{array}{c}272.4 \\
\pm 3.6\end{array}$ & 0.3087 & 1.9 & 0.04317 & 1.2 & 0.640 \\
\hline NM08-188-9 & 0.47 & 323 & 123 & 0.39 & 12.3 & $\begin{array}{c}277.5 \\
\pm 3.6\end{array}$ & $\begin{array}{c}278.7 \\
\pm 3.6\end{array}$ & $\begin{array}{c}278.9 \\
\pm 3.8\end{array}$ & 0.3197 & 2.3 & 0.04421 & 1.3 & 0.563 \\
\hline NM08-188-10 & - & 152 & 42 & 0.28 & 5.6 & $\begin{array}{l}269.5 \\
\pm 7.2\end{array}$ & $\begin{array}{c}269.2 \\
\pm 7.2\end{array}$ & $\begin{array}{c}268.6 \\
\pm 7.5\end{array}$ & 0.292 & 4.5 & 0.0426 & 2.7 & 0.606 \\
\hline NM08-188-11 & 0.22 & 686 & 382 & 0.57 & 26.5 & $\begin{array}{c}283.0 \\
\pm 3.4\end{array}$ & $\begin{array}{c}283.8 \\
\pm 3.4\end{array}$ & $\begin{array}{c}283.8 \\
\pm 3.7\end{array}$ & 0.3229 & 1.8 & 0.04501 & 1.2 & 0.687 \\
\hline NM08-73-1 & 0.12 & 645 & 375 & 0.60 & 24.1 & $\begin{array}{c}274.1 \\
\pm 2.3\end{array}$ & $\begin{array}{c}273.9 \\
\pm 2.3\end{array}$ & $\begin{array}{c}273.7 \\
\pm 2.6\end{array}$ & 0.3132 & 1.8 & 0.04344 & 0.9 & 0.519 \\
\hline NM08-73-2 & 1.43 & 514 & 450 & 0.90 & 28.3 & $\begin{array}{c}394.5 \\
\pm 3.5\end{array}$ & $\begin{array}{c}393.5 \\
\pm 3.4\end{array}$ & $\begin{array}{c}398.1 \\
\pm 4.0\end{array}$ & 0.492 & 4.6 & 0.06310 & 0.9 & 0.588 \\
\hline NM08-73-3 & 0.06 & 2456 & 441 & 0.19 & 79.4 & $\begin{array}{c}238.1 \\
\pm 1.8\end{array}$ & $\begin{array}{c}238.1 \\
\pm 1.8\end{array}$ & $\begin{array}{c}237.8 \\
\pm 1.8\end{array}$ & 0.2640 & 1.3 & 0.03762 & 0.8 & 0.703 \\
\hline NM08-73-4 & 0.18 & 1017 & 621 & 0.63 & 37.9 & $\begin{array}{c}273.2 \\
\pm 2.2\end{array}$ & $\begin{array}{l}273.5 \\
\pm 2.2\end{array}$ & $\begin{array}{c}273.9 \\
\pm 2.4\end{array}$ & 0.3047 & 1.5 & 0.04330 & 0.8 & 0.597 \\
\hline NM08-73-5 & 3.75 & 204 & 98 & 0.50 & 9.1 & $\begin{array}{c}313.4 \\
\pm 4.2\end{array}$ & $\begin{array}{c}312.4 \\
\pm 3.5\end{array}$ & $\begin{array}{c}312.5 \\
\pm 3.9\end{array}$ & 0.380 & 13.0 & 0.04982 & 1.4 & 0.231 \\
\hline NM08-73-6 & 0.17 & 241 & 141 & 0.60 & 16.1 & $\begin{array}{c}481.2 \\
\pm 4.5\end{array}$ & $\begin{array}{l}482.7 \\
\pm 4.7\end{array}$ & $\begin{array}{c}482.6 \\
\pm 5.1\end{array}$ & 0.579 & 2.0 & 0.07751 & 1.0 & 0.532 \\
\hline NM08-73-7 & 0.20 & 1009 & 560 & 0.57 & 37.6 & $\begin{array}{c}272.9 \\
\pm 2.2\end{array}$ & $\begin{array}{c}273.1 \\
\pm 2.2\end{array}$ & $\begin{array}{c}273.5 \\
\pm 2.4\end{array}$ & 0.3059 & 2.1 & 0.04325 & 0.8 & 0.606 \\
\hline NM08-73-8 & 0.08 & 530 & 34 & 0.07 & 160.0 & $\begin{array}{l}1940 \\
\pm 14\end{array}$ & $\begin{array}{c}1939 \\
\pm 16\end{array}$ & $\begin{array}{c}1,941 \\
\pm 14\end{array}$ & 5.777 & 0.9 & 0.3512 & 0.8 & 0.897 \\
\hline NM08-73-9 & 0.22 & 637 & 352 & 0.57 & 23.8 & $\begin{array}{c}274.4 \\
\pm 2.3\end{array}$ & $\begin{array}{c}274.9 \\
\pm 2.4\end{array}$ & $\begin{array}{c}274.7 \\
\pm 2.6\end{array}$ & 0.3019 & 2.6 & 0.04348 & 0.9 & 0.400 \\
\hline NM08-73-10 & 1.03 & 592 & 327 & 0.57 & 21.5 & $\begin{array}{c}264.7 \\
\pm 3.1\end{array}$ & $\begin{array}{c}264.4 \\
\pm 3.1\end{array}$ & $\begin{array}{r}264.7 \\
\pm 3.4\end{array}$ & 0.304 & 4.9 & 0.04192 & 1.2 & 0.372 \\
\hline NM08-73-11 & 2.47 & 1022 & 486 & 0.49 & 40.8 & $\begin{array}{c}285.7 \\
\pm 2.5\end{array}$ & $\begin{array}{c}284.6 \\
\pm 2.4\end{array}$ & $\begin{array}{c}284.5 \\
\pm 2.7\end{array}$ & 0.344 & 4.5 & 0.04531 & 0.9 & 0.509 \\
\hline NM08-73-12 & 1.71 & 690 & 353 & 0.53 & 26.2 & $\begin{array}{c}274.4 \\
\pm 2.9\end{array}$ & $\begin{array}{l}275.5 \\
\pm 2.4 \\
\end{array}$ & $\begin{array}{c}275.0 \\
\pm 2.6 \\
\end{array}$ & 0.290 & 12.0 & 0.04348 & 1.1 & 0.185 \\
\hline
\end{tabular}

a) $\mathrm{Pb} *$ 和 $\mathrm{Pb}_{\mathrm{c}}$ 分别代表放射成因和普通铅. 标准标定的误差为 $0.38 \%$ (不包括在上述误差中, 只在比较不同靶的数据时使用); b) 用实 测 ${ }^{204} \mathrm{~Pb}$ 校正的普通铅; c) 假设 ${ }^{206} \mathrm{~Pb} /{ }^{238} \mathrm{U}-{ }^{207} \mathrm{~Pb} /{ }^{235} \mathrm{U}$ 年龄一致的普通铅; d) 假设 ${ }^{206} \mathrm{~Pb} /{ }^{238} \mathrm{U}-{ }^{208} \mathrm{~Pb} /{ }^{232} \mathrm{Th}$ 年龄一致校正的普通铅

线上，但是相对年龄值较为集中的 $275 \mathrm{Ma}$ 年龄值偏 高, 其所指示的地质意义还需要进一步研究. 3 号、 10 号锆石均落在了谐和线上, 但年龄偏小, 可能受到后 期热事件影响. 其他 5 颗锆石测定的年龄均较稳定, 集中分布于 $274 \mathrm{Ma}$ 附近, 年龄的加权平均值为 $(273.7 \pm 1.0) \mathrm{Ma}$ ，代表了火山岩锆石的结晶年龄.

\section{3 岩石地球化学特征}

从岩石标本中挑选了 16 件新鲜的有代表性的样 品进行了主量元素、稀土元素、微量元素地球化学分 析, 其中玄武岩样品 8 件, 辉长岩样品 8 件. 并挑选 了 4 件玄武岩样品进行了 $\mathrm{Sr}, \mathrm{Nd}$ 和 $\mathrm{Pb}$ 同位素地球化 
表 2 满都拉基性岩地球化学分析结果 ${ }^{\text {a) }}$

\begin{tabular}{|c|c|c|c|c|c|c|c|c|}
\hline 样品号 & NM08-186 & NM08-188 & NM08-190 & NM08-192 & NM08-195 & NM08-196 & NM08-197 & NM08-198 \\
\hline 岩性 & 辉长岩 & 辉长岩 & 辉长岩 & 辉长岩 & 辉长岩 & 辉长岩 & 辉绿岩 & 辉绿岩 \\
\hline $\mathrm{SiO}_{2}$ & 52.06 & 49.90 & 55.04 & 51.16 & 47.26 & 46.87 & 51.80 & 51.15 \\
\hline $\mathrm{TiO}_{2}$ & 0.78 & 1.20 & 1.22 & 1.23 & 0.78 & 2.92 & 0.86 & 1.20 \\
\hline $\mathrm{Al}_{2} \mathrm{O}_{3}$ & 14.90 & 17.41 & 15.63 & 16.96 & 16.12 & 13.81 & 15.07 & 14.42 \\
\hline $\mathrm{Fe}_{2} \mathrm{O}_{3}^{\mathrm{T}}$ & 11.14 & 13.82 & 12.64 & 13.32 & 9.64 & 16.20 & 12.38 & 14.34 \\
\hline $\mathrm{MnO}$ & 0.23 & 0.23 & 0.19 & 0.27 & 0.13 & 0.19 & 0.19 & 0.19 \\
\hline $\mathrm{MgO}$ & 5.62 & 2.75 & 2.12 & 2.87 & 7.62 & 5.27 & 5.44 & 4.91 \\
\hline $\mathrm{CaO}$ & 10.85 & 9.42 & 6.65 & 8.92 & 13.41 & 8.94 & 6.93 & 7.16 \\
\hline $\mathrm{Na}_{2} \mathrm{O}$ & 1.68 & 2.09 & 3.38 & 1.94 & 1.64 & 3.45 & 4.54 & 2.93 \\
\hline $\mathrm{K}_{2} \mathrm{O}$ & 0.07 & 0.15 & 0.30 & 0.03 & 0.01 & 0.30 & 0.04 & 0.02 \\
\hline $\mathrm{P}_{2} \mathrm{O}_{5}$ & 0.12 & 0.41 & 0.31 & 0.33 & 0.02 & 0.09 & 0.06 & 0.08 \\
\hline LOI & 2.48 & 2.59 & 2.47 & 2.92 & 3.25 & 1.86 & 2.62 & 3.51 \\
\hline 总量 & 99.92 & 99.95 & 99.96 & 99.95 & 99.89 & 99.90 & 99.93 & 99.91 \\
\hline $\mathrm{Mg}^{\#}$ & 0.50 & 0.28 & 0.25 & 0.30 & 0.61 & 0.39 & 0.47 & 0.41 \\
\hline $\mathrm{Cr}$ & 257 & 3.66 & 21.7 & 3.45 & 444 & 19.6 & 27.7 & 9.3 \\
\hline Co & 24.8 & 22.8 & 19.5 & 24.2 & 41.1 & 44.5 & 36.2 & 42.6 \\
\hline $\mathrm{Ni}$ & 55.5 & 5.12 & 9.84 & 2.4 & 110 & 37.5 & 21.9 & 12.1 \\
\hline $\mathrm{Ga}$ & 19.4 & 21.6 & 19.5 & 20.3 & 16.7 & 19.5 & 15.5 & 17.9 \\
\hline $\mathrm{Sc}$ & 39.9 & 35.2 & 49.7 & 46.2 & 46.8 & 41.00 & 39.0 & 43.5 \\
\hline $\mathrm{V}$ & 141 & 63.1 & 98.6 & 75.5 & 310 & 565 & 324 & 482 \\
\hline $\mathrm{Rb}$ & 1.16 & 2.72 & 5.45 & 0.864 & 0.595 & 2.89 & 0.853 & 0.473 \\
\hline $\mathrm{Sr}$ & 174 & 199 & 167 & 173 & 235 & 130 & 118 & 202 \\
\hline $\mathrm{Y}$ & 16.5 & 15.3 & 22.8 & 20.0 & 12.4 & 29.1 & 18.6 & 21.2 \\
\hline $\mathrm{Zr}$ & 49.7 & 37.5 & 37.3 & 32.7 & 33.4 & 82.5 & 52.5 & 54.7 \\
\hline $\mathrm{Nb}$ & 1.08 & 0.527 & 0.619 & 0.845 & 0.280 & 0.840 & 0.376 & 0.427 \\
\hline $\mathrm{Ba}$ & 86.0 & 58.6 & 114 & 24.3 & 34.1 & 53.2 & 37.1 & 43.4 \\
\hline Hf & 1.43 & 1.18 & 1.44 & 1.17 & 1.09 & 2.81 & 1.76 & 1.94 \\
\hline $\mathrm{Ta}$ & 0.070 & 0.046 & 0.042 & 0.060 & 0.018 & 0.060 & 0.032 & 0.032 \\
\hline W & 0.177 & 0.298 & 0.178 & 0.154 & 0.054 & 0.049 & 0.084 & 0.053 \\
\hline $\mathrm{Pb}$ & 2.52 & 2.40 & 1.46 & 1.62 & 0.894 & 0.572 & 2.03 & 0.827 \\
\hline $\mathrm{Th}$ & 0.525 & 0.421 & 0.351 & 0.356 & 0.052 & 0.13 & 0.335 & 0.270 \\
\hline $\mathrm{U}$ & 0.277 & 0.351 & 0.484 & 0.400 & 0.187 & 0.237 & 0.209 & 0.500 \\
\hline $\mathrm{La}$ & 2.52 & 2.99 & 2.83 & 2.41 & 0.933 & 2.64 & 1.83 & 2.48 \\
\hline $\mathrm{Ce}$ & 5.61 & 7.14 & 7.09 & 5.95 & 2.28 & 6.74 & 4.30 & 5.89 \\
\hline $\operatorname{Pr}$ & 0.912 & 1.22 & 1.29 & 1.04 & 0.482 & 1.31 & 0.781 & 1.06 \\
\hline $\mathrm{Nd}$ & 4.81 & 6.46 & 7.34 & 5.75 & 2.98 & 7.56 & 4.52 & 5.66 \\
\hline $\mathrm{Sm}$ & 1.66 & 2.05 & 2.47 & 2.10 & 1.12 & 2.71 & 1.60 & 1.99 \\
\hline $\mathrm{Eu}$ & 0.927 & 1.03 & 1.26 & 1.08 & 0.666 & 1.12 & 0.69 & 0.79 \\
\hline Gd & 2.08 & 2.36 & 3.24 & 2.63 & 1.52 & 3.39 & 2.14 & 2.51 \\
\hline $\mathrm{Tb}$ & 0.420 & 0.433 & 0.645 & 0.551 & 0.321 & 0.757 & 0.434 & 0.527 \\
\hline Dy & 2.81 & 2.70 & 4.19 & 3.54 & 2.18 & 4.95 & 3.04 & 3.57 \\
\hline Ho & 0.630 & 0.605 & 0.894 & 0.741 & 0.468 & 1.11 & 0.667 & 0.792 \\
\hline $\mathrm{Er}$ & 1.87 & 1.70 & 2.52 & 2.14 & 1.37 & 3.26 & 2.09 & 2.41 \\
\hline $\mathrm{Tm}$ & 0.299 & 0.252 & 0.38 & 0.347 & 0.213 & 0.509 & 0.311 & 0.367 \\
\hline $\mathrm{Yb}$ & 2.14 & 1.55 & 2.37 & 2.20 & 1.44 & 3.25 & 2.08 & 2.40 \\
\hline $\mathrm{Lu}$ & 0.335 & 0.226 & 0.341 & 0.327 & 0.219 & 0.467 & 0.311 & 0.352 \\
\hline $\mathrm{La} / \mathrm{Nb}$ & 2.33 & 5.67 & 4.57 & 2.85 & 3.33 & 3.14 & 4.87 & 5.81 \\
\hline $\mathrm{Nb} / \mathrm{U}$ & 3.90 & 1.50 & 1.28 & 2.11 & 1.50 & 3.54 & 1.80 & 0.85 \\
\hline$(\mathrm{La} / \mathrm{Yb})_{\mathrm{N}}$ & 0.84 & 1.38 & 0.86 & 0.79 & 0.46 & 0.58 & 0.63 & 0.74 \\
\hline$\Sigma \mathrm{REE}$ & 27.02 & 30.72 & 36.86 & 30.81 & 16.19 & 39.77 & 24.79 & 30.80 \\
\hline$\delta \mathrm{Ce}$ & 0.91 & 0.92 & 0.91 & 0.92 & 0.83 & 0.89 & 0.88 & 0.89 \\
\hline$\delta \mathrm{Eu}$ & 1.53 & 1.43 & 1.36 & 1.40 & 1.56 & 1.13 & 1.14 & 1.08 \\
\hline
\end{tabular}


晨辰等: 内蒙古达茂旗满都拉地区早二叠世基性岩的年代学、地球化学及其地质意义

(续表 2)

\begin{tabular}{|c|c|c|c|c|c|c|c|c|}
\hline 样品号 & NM08-067 & NM08-068 & NM08-069 & NM08-070 & NM08-071 & NM08-072 & NM08-073 & NM08-074 \\
\hline 岩性 & 玄武岩 & 玄武岩 & 玄武岩 & 玄武岩 & 玄武岩 & 玄武岩 & 玄武岩 & 玄武岩 \\
\hline $\mathrm{SiO}_{2}$ & 54.40 & 52.86 & 50.95 & 49.40 & 47.69 & 51.87 & 50.27 & 48.51 \\
\hline $\mathrm{TiO}_{2}$ & 0.58 & 0.60 & 0.61 & 0.84 & 0.88 & 0.30 & 0.28 & 0.78 \\
\hline $\mathrm{Al}_{2} \mathrm{O}_{3}$ & 15.92 & 16.58 & 15.86 & 14.30 & 14.33 & 16.41 & 16.16 & 14.98 \\
\hline $\mathrm{Fe}_{2} \mathrm{O}_{3}{ }^{\mathrm{T}}$ & 11.17 & 12.15 & 11.59 & 10.53 & 11.01 & 9.12 & 9.59 & 10.41 \\
\hline $\mathrm{MnO}$ & 0.20 & 0.20 & 0.16 & 0.13 & 0.14 & 0.13 & 0.14 & 0.14 \\
\hline $\mathrm{MgO}$ & 5.31 & 6.25 & 5.02 & 6.53 & 7.84 & 5.25 & 5.63 & 7.53 \\
\hline $\mathrm{CaO}$ & 3.34 & 1.45 & 7.79 & 10.56 & 10.83 & 9.44 & 10.72 & 12.15 \\
\hline $\mathrm{Na}_{2} \mathrm{O}$ & 4.72 & 4.36 & 3.32 & 3.39 & 2.38 & 2.04 & 2.05 & 1.34 \\
\hline $\mathrm{K}_{2} \mathrm{O}$ & 0.40 & 1.47 & 0.06 & 0.07 & 0.26 & 0.08 & 0.04 & 0.31 \\
\hline $\mathrm{P}_{2} \mathrm{O}_{5}$ & 0.02 & 0.02 & 0.02 & 0.13 & 0.08 & 0.03 & 0.02 & 0.05 \\
\hline LOI & 3.88 & 4.00 & 4.54 & 4.02 & 4.44 & 5.28 & 5.04 & 3.69 \\
\hline 总量 & 99.95 & 99.94 & 99.93 & 99.90 & 99.89 & 99.94 & 99.94 & 99.89 \\
\hline $\mathrm{Mg}^{\#}$ & 0.49 & 0.51 & 0.46 & 0.55 & 0.59 & 0.53 & 0.54 & 0.59 \\
\hline $\mathrm{Cr}$ & 8.67 & 22.9 & 95.4 & 504 & 383 & 58.7 & 60.5 & 394 \\
\hline Co & 40.2 & 52.7 & 38.0 & 47.6 & 49.4 & 41.2 & 42.9 & 46.8 \\
\hline $\mathrm{Ni}$ & 14.0 & 18.7 & 30.1 & 123 & 140 & 23.8 & 26.7 & 127 \\
\hline $\mathrm{Ga}$ & 13.2 & 12.5 & 14.9 & 13.9 & 15.1 & 14.3 & 14.6 & 16.2 \\
\hline $\mathrm{Sc}$ & 45.1 & 44.7 & 46.6 & 38.3 & 37.7 & 38.1 & 42.4 & 37.00 \\
\hline $\mathrm{V}$ & 186 & 189 & 309 & 330 & 344 & 265 & 287 & 320 \\
\hline $\mathrm{Rb}$ & 10.1 & 45.4 & 1.35 & 1.91 & 5.56 & 2.42 & 1.56 & 8.20 \\
\hline $\mathrm{Sr}$ & 112 & 86.7 & 61.8 & 75.9 & 127 & 142 & 90.1 & 309 \\
\hline $\mathrm{Y}$ & 10.6 & 11.7 & 14.1 & 22.9 & 23.3 & 11.5 & 12.4 & 18.7 \\
\hline $\mathrm{Zr}$ & 53.1 & 62.3 & 59.5 & 80.2 & 84.7 & 38.4 & 43.5 & 65.8 \\
\hline $\mathrm{Nb}$ & 0.641 & 0.799 & 0.915 & 0.448 & 0.538 & 0.247 & 0.240 & 0.307 \\
\hline $\mathrm{Ba}$ & 40.8 & 100 & 16.7 & 16.0 & 19.4 & 27.9 & 20.6 & 23.5 \\
\hline $\mathrm{Hf}$ & 2.01 & 2.29 & 2.21 & 2.91 & 3.14 & 1.65 & 1.60 & 2.36 \\
\hline $\mathrm{Ta}$ & 0.060 & 0.069 & 0.075 & 0.033 & 0.039 & 0.024 & 0.027 & 0.030 \\
\hline W & 0.108 & 0.107 & 0.179 & 0.067 & 0.026 & 0.067 & 0.045 & 0.040 \\
\hline $\mathrm{Pb}$ & 2.24 & 1.90 & 2.52 & 1.28 & 1.35 & 1.52 & 1.18 & 1.40 \\
\hline Th & 0.580 & 0.653 & 0.663 & 0.330 & 0.358 & 0.368 & 0.356 & 0.326 \\
\hline $\mathrm{U}$ & 0.507 & 0.545 & 1.17 & 0.352 & 0.513 & 0.422 & 0.628 & 0.212 \\
\hline $\mathrm{La}$ & 1.85 & 1.67 & 2.39 & 2.37 & 2.40 & 1.54 & 1.75 & 1.56 \\
\hline $\mathrm{Ce}$ & 4.98 & 4.77 & 5.12 & 5.29 & 6.04 & 2.97 & 3.17 & 4.11 \\
\hline $\operatorname{Pr}$ & 0.578 & 0.656 & 0.878 & 1.05 & 1.15 & 0.538 & 0.612 & 0.775 \\
\hline $\mathrm{Nd}$ & 2.66 & 3.05 & 4.38 & 5.82 & 6.32 & 2.80 & 3.20 & 4.38 \\
\hline $\mathrm{Sm}$ & 0.893 & 1.15 & 1.35 & 1.92 & 2.22 & 1.02 & 1.13 & 1.66 \\
\hline $\mathrm{Eu}$ & 0.373 & 0.423 & 0.497 & 0.782 & 0.91 & 0.449 & 0.462 & 0.671 \\
\hline $\mathrm{Gd}$ & 1.33 & 1.41 & 1.80 & 2.64 & 2.80 & 1.37 & 1.56 & 2.30 \\
\hline $\mathrm{Tb}$ & 0.275 & 0.325 & 0.374 & 0.545 & 0.607 & 0.298 & 0.335 & 0.468 \\
\hline Dy & 2.01 & 2.36 & 2.64 & 3.80 & 4.26 & 2.13 & 2.29 & 3.32 \\
\hline Но & 0.453 & 0.532 & 0.575 & 0.861 & 0.940 & 0.457 & 0.504 & 0.731 \\
\hline $\mathrm{Er}$ & 1.36 & 1.72 & 1.81 & 2.63 & 2.68 & 1.40 & 1.54 & 2.12 \\
\hline $\mathrm{Tm}$ & 0.226 & 0.288 & 0.283 & 0.428 & 0.424 & 0.209 & 0.246 & 0.348 \\
\hline $\mathrm{Yb}$ & 1.60 & 1.95 & 1.94 & 2.93 & 2.84 & 1.56 & 1.67 & 2.29 \\
\hline $\mathrm{Lu}$ & 0.229 & 0.298 & 0.297 & 0.449 & 0.443 & 0.229 & 0.258 & 0.332 \\
\hline $\mathrm{La} / \mathrm{Nb}$ & 2.89 & 2.09 & 2.61 & 5.29 & 4.46 & 6.23 & 7.29 & 5.08 \\
\hline $\mathrm{Nb} / \mathrm{U}$ & 1.26 & 1.47 & 0.78 & 1.27 & 1.05 & 0.59 & 0.38 & 1.45 \\
\hline$(\mathrm{La} / \mathrm{Yb})_{\mathrm{N}}$ & 0.83 & 0.61 & 0.88 & 0.58 & 0.61 & 0.71 & 0.75 & 0.49 \\
\hline$\sum$ REE & 18.82 & 20.60 & 24.33 & 31.52 & 34.03 & 16.97 & 18.73 & 25.07 \\
\hline$\delta \mathrm{Ce}$ & 1.18 & 1.12 & 0.87 & 0.82 & 0.89 & 0.80 & 0.75 & 0.92 \\
\hline$\delta \mathrm{Eu}$ & 1.05 & 1.02 & 0.97 & 1.06 & 1.12 & 1.16 & 1.06 & 1.05 \\
\hline
\end{tabular}

石标准化比值 
表 3 满都拉玄武岩 $\mathrm{Sr}-\mathrm{Nd}$ 同位素组成 a)

\begin{tabular}{|c|c|c|c|c|c|c|c|c|c|c|c|c|c|}
\hline 样品号 & $\begin{array}{c}\mathrm{Rb} \\
(\mathrm{ppm})\end{array}$ & $\mathrm{Sr}(\mathrm{ppm})$ & ${ }^{87} \mathrm{Rb} /{ }^{86} \mathrm{Sr}$ & $\left({ }^{87} \mathrm{Sr} /{ }^{86} \mathrm{Sr}\right)_{\mathrm{m}}$ & & $\left({ }^{87} \mathrm{Sr} /{ }^{86} \mathrm{Sr}\right)_{\mathrm{i}}$ & $\begin{array}{c}\text { Sm } \\
(\mathrm{ppm})\end{array}$ & $\begin{array}{c}\mathrm{Nd} \\
(\mathrm{ppm})\end{array}$ & $\begin{array}{l}{ }^{147} \mathrm{Sm} / \\
{ }^{144} \mathrm{Nd}\end{array}$ & $\left({ }^{143} \mathrm{Nd} /{ }^{144} \mathrm{Nd}\right)_{\mathrm{m}}$ & $2 \sigma$ & $\left({ }^{143} \mathrm{Nd} /{ }^{144} \mathrm{Nd}\right)$ & $\varepsilon_{\mathrm{Nd}}(t)$ \\
\hline NM08-067 & 9.06 & 121.00 & 0.2160 & 0.705741 & 26 & 0.70490 & 0.52 & 4.40 & 0.0715 & 0.512744 & 8 & 0.51262 & 6.4 \\
\hline NM08-068 & 37.40 & 74.80 & 1.4472 & 0.711007 & 19 & 0.70537 & 0.99 & 3.80 & 0.1571 & 0.512742 & 6 & 0.51246 & 3.4 \\
\hline NM08-070 & 1.42 & 76.10 & 0.0540 & 0.705271 & 27 & 0.70506 & 2.38 & 8.70 & 0.1647 & 0.512991 & 5 & 0.51270 & 8.0 \\
\hline NM08-073 & 1.18 & 84.00 & 0.0407 & 0.705097 & 11 & 0.70494 & 1.07 & 4.00 & 0.1629 & 0.512882 & 6 & 0.51259 & 5.9 \\
\hline
\end{tabular}

a) $\varepsilon_{\mathrm{Nd}}(t)=\left[\left({ }^{143} \mathrm{Nd} /{ }^{144} \mathrm{Nd}\right)_{\mathrm{i}} /\left({ }^{143} \mathrm{Nd} /{ }^{144} \mathrm{Nd}\right)_{\text {CHUR.i }}-1\right] \times 10^{4}$; 所用参数为 $\left({ }^{143} \mathrm{Nd} / /^{144} \mathrm{Nd}\right)_{\text {CHUR.m }}=0.512638 ;\left({ }^{147} \mathrm{Sm} /{ }^{144} \mathrm{Nd}\right)_{\text {CHUR.m }}=0.1967 ;$ 下角 $\mathrm{m}$ 代表样品测试值, 下角 $\mathrm{i}$ 代表初始值; 玄武岩的年龄 $t=274 \mathrm{Ma}$

表 4 满都拉玄武岩 $\mathbf{P b}$ 同位素组成 ${ }^{\text {a) }}$

\begin{tabular}{cccccccccc}
\hline 样品 & $\mathrm{Pb}(\mathrm{ppm})$ & $\mathrm{Th}(\mathrm{ppm})$ & $\mathrm{U}(\mathrm{ppm})$ & $\left({ }^{206} \mathrm{~Pb} /{ }^{204} \mathrm{~Pb}\right)_{\mathrm{m}}$ & $\left({ }^{207} \mathrm{~Pb} /{ }^{204} \mathrm{~Pb}\right)_{\mathrm{m}}$ & $\left({ }^{208} \mathrm{~Pb} /{ }^{204} \mathrm{~Pb}\right)_{\mathrm{m}}$ & $\left({ }^{206} \mathrm{~Pb} /{ }^{204} \mathrm{~Pb}\right)_{\mathrm{i}}$ & $\left({ }^{207} \mathrm{~Pb} /{ }^{204} \mathrm{~Pb}\right)_{\mathrm{i}}$ & $\left({ }^{208} \mathrm{~Pb} /{ }^{204} \mathrm{~Pb}\right)_{\mathrm{i}}$ \\
\hline NM08-067 & 2.24 & 0.58 & 0.51 & 18.45 & 15.54 & 38.17 & 17.84 & 15.51 & 37.94 \\
NM08-068 & 1.90 & 0.65 & 0.55 & 18.67 & 15.54 & 38.33 & 17.89 & 15.50 & 38.02 \\
NM08-070 & 1.28 & 0.33 & 0.35 & 18.67 & 15.55 & 38.18 & 17.93 & 15.51 & 37.94 \\
NM08-073 & 1.18 & 0.36 & 0.63 & 18.82 & 15.53 & 38.39 & 17.39 & 15.46 & 37.86 \\
\hline
\end{tabular}

a) $\left.\left({ }^{206} \mathrm{~Pb}^{1204} \mathrm{~Pb}\right)_{\mathrm{i}},{ }^{(207} \mathrm{Pb} /{ }^{204} \mathrm{~Pb}\right)_{\mathrm{i}},\left({ }^{208} \mathrm{~Pb} /{ }^{204} \mathrm{~Pb}\right)_{\mathrm{i}}$ 为进行时间校正后的初始值; 玄武岩年龄 $=274 \mathrm{Ma}$

学分析. 主元素含量在北京大学造山带与地壳演化 教育部重点实验室进行 $\mathrm{X}$ 光苂光光谱 $(X R F)$ 分析, 主 元素精度可达 $1 \%$ 以内. 微量、稀土元素在核工业北 京地质研究院电感耦合等离子质谱仪(ICP-MS) 测定, 除 $\mathrm{Nb}$ 和 $\mathrm{Ta}$ 精度在 $9 \%$ 以内, 其他微量元素通常在 $5 \%$ 以内. 分析结果见表 2. 同位素数据在核工业北京地 质研究所分析测试中心利用 ISOPROBE-T 热电离质 谱仪测试. 分析结果见表 3 和 4.

\section{1 主量元素特征}

从总体上看, 本区样品的 $\mathrm{SiO}_{2}$ 含量变化范围不 大, 辉长、辉绿岩样品变化范围为 $46.87 \%$ 55.04\%, 玄武岩样品变化范围为 47.69\% 54.40\%. 在 TAS 图 解(图 5)中样品点基本落入玄武岩-辉长岩区, 个别落 入玄武安山岩-闪长岩区, 属于亚碱性岩石系列; 在 AFM 图解(图 6)中主要落入拉斑玄武岩区, 个别落入 钻碱性玄武岩区.

辉长、辉绿岩样品中 $\mathrm{TiO}_{2}$ 含量较低, 变化范围 为 $0.78 \% \sim 2.92 \% ; \mathrm{Al}_{2} \mathrm{O}_{3}$ 含量较高, 变化于 $13.81 \%$ $17.41 \%$ 之间; $\mathrm{Fe}_{2} \mathrm{O}_{3}{ }^{\mathrm{T}}$ 含量变化范围为 $9.64 \% \sim 16.20 \%$; $\mathrm{MgO}$ 含量变化于 $2.12 \% \sim 7.62 \%$ 之间, $\mathrm{CaO}$ 含量变化于 $6.65 \% \sim 13.41 \%$ 之间; $\mathrm{K}_{2} \mathrm{O}+\mathrm{Na}_{2} \mathrm{O}$ 含量平均值为 $3.00 \%$; $\mathrm{P}_{2} \mathrm{O}_{5}$ 含量变化范围为 $0.02 \% \sim 0.41 \% ; \mathrm{Mg}^{\#}$ 介于 $25 \sim 61$ 之间.

玄武岩样品主量元素特征与辉长、辉绿岩样品相 似, 含有较高的 $\mathrm{Al}_{2} \mathrm{O}_{3}\left(14.30 \% \sim 16.58 \%\right.$ ) 和 $\mathrm{Fe}_{2} \mathrm{O}_{3}{ }^{\mathrm{T}}$ (平

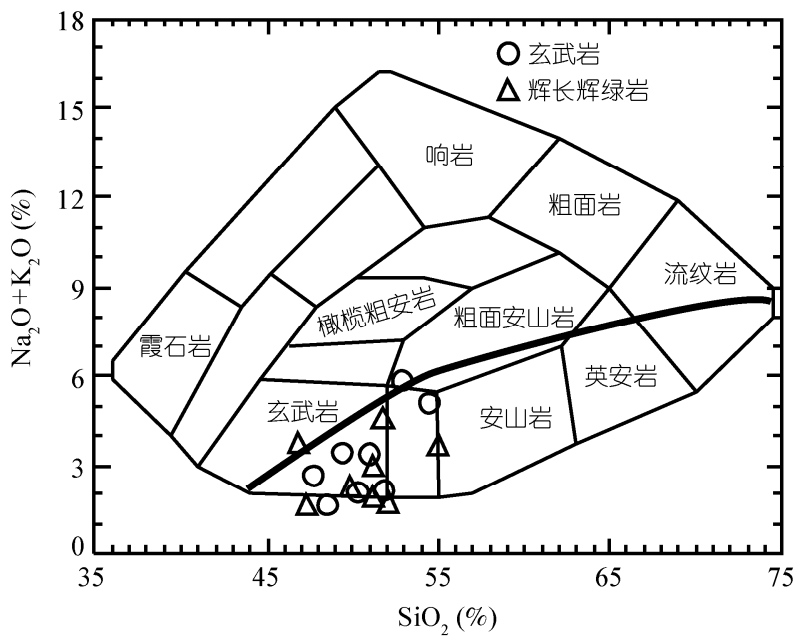

图 5 满都拉基性岩的 TAS 图解

岩石边界类型引自文献[39], 碱性和亚碱性岩石分布区域的分界线 (粗线)引自文献[40]. 圆圈为玄武岩; 三角为辉长辉绿岩, 以下图中 图例同图 5

均值为 $10.69 \%)$, 较低的 $\mathrm{TiO}_{2}(0.28 \% \sim 0.88 \%)$ 和 $\mathrm{P}_{2} \mathrm{O}_{5}$ $(0.02 \% \sim 0.13 \%) ; \mathrm{MgO}$ 和 $\mathrm{K}_{2} \mathrm{O}+\mathrm{Na}_{2} \mathrm{O}$ 含量的平均值分 别为 $6.17 \%$ 和 $3.29 \% ; \mathrm{CaO}$ 含量变化范围较大, 分布 于 $1.45 \%$ 12.15\%之间; $\mathrm{Mg}^{\#}$ 分布较集中, 平均值为 53.

\section{2 稀土元素特征}

总体上看, 辉长、辉绿岩样品的稀土元素总量较 低, $\Sigma R E E$ 变化在 16.19 39.77 ppm 之间, 平均值为 


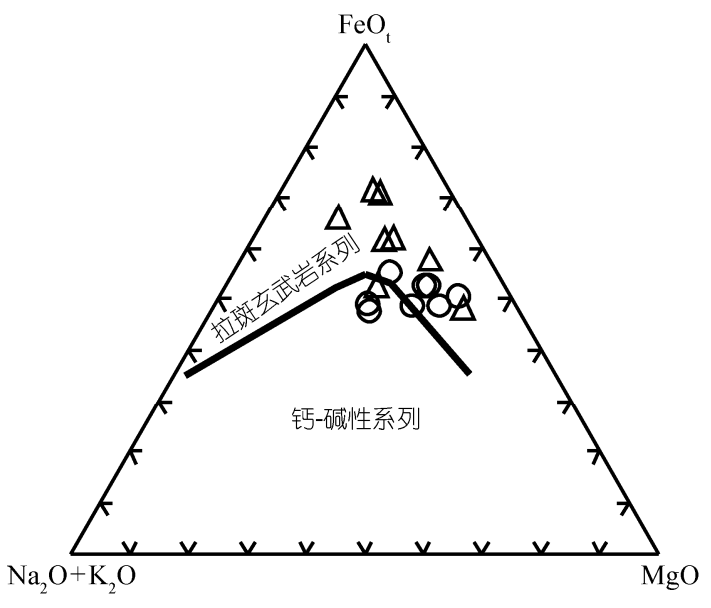

图 6 满都拉基性岩的 AFM 图解

表示䥻碱性岩石和拉斑玄武岩分布区域的界线引自文献[41]
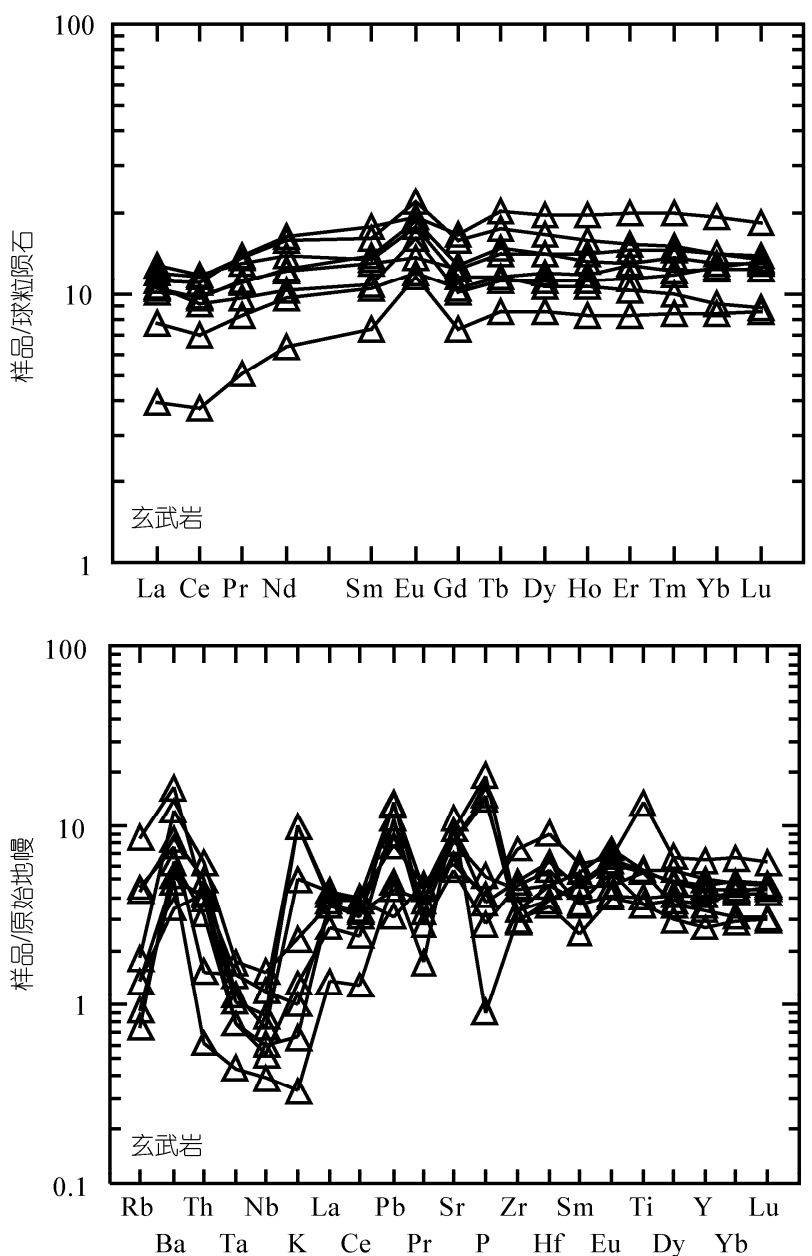

$29.62 \mathrm{ppm},(\mathrm{La} / \mathrm{Yb})_{\mathrm{N}}=0.46 \sim 1.38$ ，一般在 $0.60 \sim 0.85$ 之 间，轻重稀土分异不是非常明显，除样品 NM08-188 外其他样品的 $(\mathrm{La} / \mathrm{Yb})_{\mathrm{N}}$ 值均小于 1 . 总体呈 LREE 轻 度亏损、HREE 轻度富集的向左倾斜的斜线(图 7). $\delta \mathrm{Eu}$ 变化范围为 $1.08 \sim 1.56$, 大多数样品具有比较明 显的 $\mathrm{Eu}$ 的正异常，说明斜长石分离结晶作用不明显. $\delta \mathrm{Ce}$ 变化在 0.83 0.92, 具有较明显的 $\mathrm{Ce}$ 的负异常.

玄武岩样品的稀土元素总量也较低, $\Sigma$ REE 变化 在 16.97 34.03 ppm 之间, 平均值为 $23.76 \mathrm{ppm}$, 轻重 稀土分异不太明显, $(\mathrm{La} / \mathrm{Yb})_{\mathrm{N}}=0.49 \sim 0.88$, 总体也呈 LREE 轻度亏损、 HREE 轻度富集的向左倾斜的斜线 (图 7). $\delta \mathrm{Eu}$ 值较集中, 变化范围为 $0.97 \sim 1.16$, 平均值 为 1.06 , 样品基本无 $\mathrm{Eu}$ 异常. $\delta \mathrm{Ce}$ 除了样品 NM08067 和 NM08-068 具有轻微的 Ce 正异常外, 大部分样
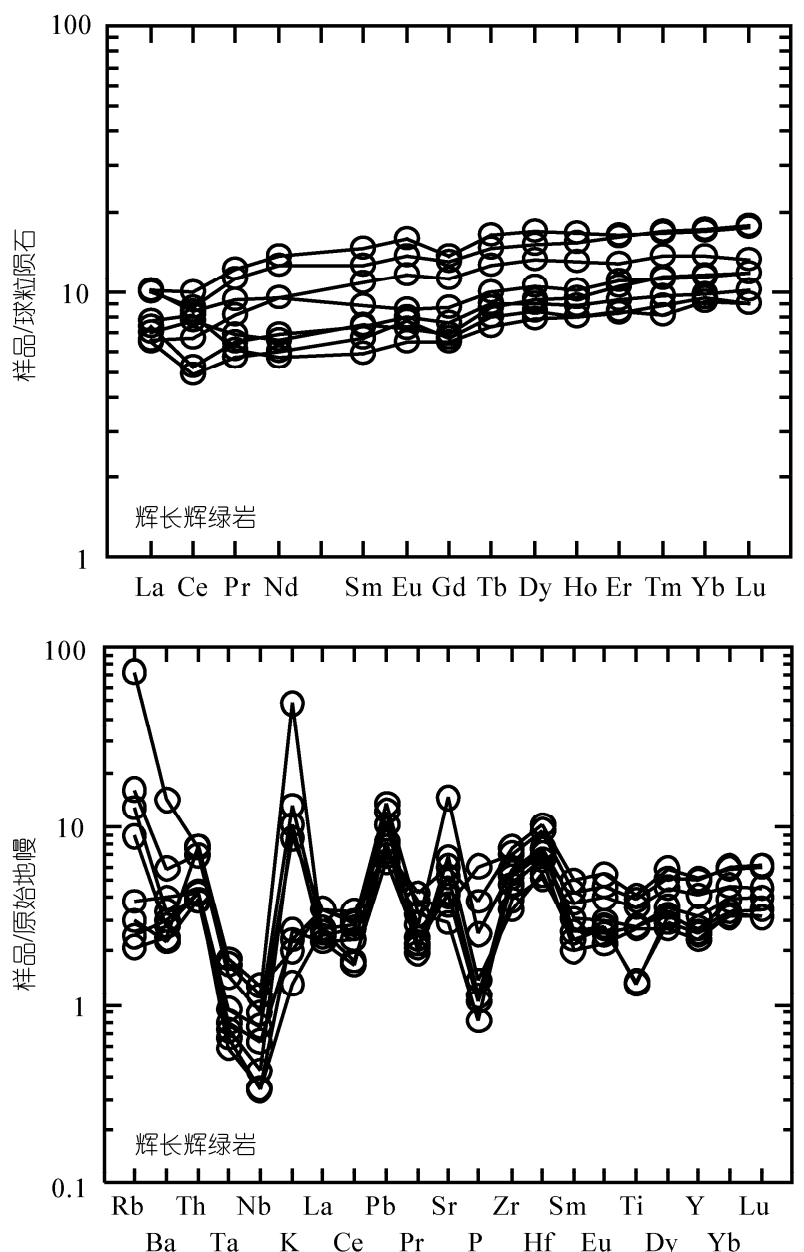

图 7 满都拉基性岩稀土元素球粒陨石标准化图解和微量元素原始地幔标准化图解 标准化值据文献[42] 
品具有较明显的 $\mathrm{Ce}$ 的负异常, 平均值为 0.84 .

\section{3 微量元素特征}

从原始地幔标准化的微量元素蛛网图(图 7)可以 看出, 辉绿、辉长岩样品除 $\mathrm{P}$ 和 $\mathrm{Ti}$ 外, 其他微量元素 含量趋势基本一致, 普遍富集 $\mathrm{Ba}$ 和 $\mathrm{Sr}$ 等大离子亲石 元素(LILE), $\mathrm{Rb}$ 相对于 $\mathrm{Ba}$ 略有亏损, 部分样品 $\mathrm{K}$ 有 亏损. 样品相对亏损 $\mathrm{Nb}$ 和 $\mathrm{Ta}$, 有明显的 $\mathrm{Nb}$ 和 $\mathrm{Ta}$ 负 异常, 部分样品 $\mathrm{P}$ 和 $\mathrm{Ti}$ 有微弱的负异常. 玄武岩样品 微量元素分布特征与辉绿、辉长岩样品较相似, 普遍 富集 $\mathrm{Rb}, \mathrm{K}$ 和 $\mathrm{Sr}$ 等大离子亲石元素(LILE), 部分样品 中的 $\mathrm{Ba}$ 相对于 $\mathrm{Rb}$ 和 $\mathrm{Th}$ 略有亏损. 样品相对亏损 $\mathrm{Nb}$, $\mathrm{Ta}, \mathrm{P}$ 和 $\mathrm{Ti}$ 等高场强元素(HFSE), $\mathrm{Nb}$ 和 $\mathrm{Ta}$ 有明显的 负异常, $\mathrm{P}$ 和 $\mathrm{Ti}$ 有微弱的负异常.

\section{4 $\mathrm{Sr}, \mathrm{Nd}$ 和 Pb 同位素特征}

玄武岩样品同位素值见表 3 和 4. 四件样品的 ${ }^{87} \mathrm{Rb} /{ }^{86} \mathrm{Sr}$ 值相差较大, 分布范围为 $0.04 \sim 1.44$, $\left({ }^{87} \mathrm{Sr} /{ }^{86} \mathrm{Sr}\right)_{\mathrm{m}}$ 为 $0.70510 \sim 0.71101,{ }^{147} \mathrm{Sm} /{ }^{144} \mathrm{Nd}$ 为 $0.0715 \sim 0.1647,\left({ }^{143} \mathrm{Nd} /{ }^{144} \mathrm{Nd}\right)_{\mathrm{m}}$ 为 $0.51274 \sim 0.51299$. 经 计算后四个样品的 $\left({ }^{87} \mathrm{Sr} /{ }^{86} \mathrm{Sr}\right)_{\mathrm{i}}$ 为 $0.70490 \sim 0.70537$, $\left({ }^{143} \mathrm{Nd} /{ }^{144} \mathrm{Nd}\right)_{\mathrm{i}}$ 为 $0.51262 \sim 0.51270, \varepsilon_{\mathrm{Nd}}(t)$ 为 3.4 8.0, $\left({ }^{206} \mathrm{~Pb} /{ }^{204} \mathrm{~Pb}\right)_{\mathrm{i}}$ 为 $17.39 \sim 17.93,\left({ }^{207} \mathrm{~Pb} /{ }^{204} \mathrm{~Pb}\right)_{\mathrm{i}}$ 为 $15.46 \sim$ $15.51,\left({ }^{208} \mathrm{~Pb} /{ }^{204} \mathrm{~Pb}\right)_{\mathrm{i}}$ 为 $37.86 \sim 38.02$. 总体可以看出, 玄武岩样品具有相对中等的 $\left({ }^{87} \mathrm{Sr} /{ }^{86} \mathrm{Sr}\right)_{\mathrm{i}}$ 值、中等正的 $\varepsilon_{\mathrm{Nd}}(t)$ 值、中等的 $\left({ }^{206} \mathrm{~Pb} /{ }^{204} \mathrm{~Pb}\right)$ 值.

\section{4 讨论}

\section{1 元素活动性分析}

薄片研究表明, 辉长、辉绿岩及玄武岩样品较新 鲜, 蚀变程度较低. 但部分基性岩样品的 LOI 偏高 (>3\%), 说明一些样品可能受到了成岩后期的热液蚀 变作用. 在火山岩与热液相互作用引起的低级蚀变 和变质过程中, $\mathrm{Zr}$ 元素不易发生扰动, 因此常被用来 判断其他示踪元素的活动性 ${ }^{[43,44]}$. 利用 $\mathrm{Zr}$ 做横坐标, $\mathrm{Rb}, \mathrm{Ba}, \mathrm{Sr}, \mathrm{U}, \mathrm{Nd}, \mathrm{La}$ 和 $\mathrm{Sm}$ 等元素作纵坐标作图(图 略)来判断这些元素的活动性. $\mathrm{Rb}, \mathrm{Ba}$ 和 $\mathrm{Sr}$ 等大离子 亲石元素与 $\mathrm{Zr}$ 呈较好的相关性; 同位素元素 $\mathrm{U}$ 和 $\mathrm{Zr}$ 存在着一定的相关关系, $\mathrm{Nd}$ 和 $\mathrm{Zr}$ 有很好的正相关; $\mathrm{La}$ 和 $\mathrm{Sm}$ 等 REE 元素均与 $\mathrm{Zr}$ 呈很好的正相关性. 综 上所述, REE 和 $\mathrm{Nd}$ 同位素体系在岩浆后期没有随蚀
变而产生明显变化, 因此可利用其地球化学特征来 示踪源区; $\operatorname{LILE}(\mathrm{Rb}, \mathrm{Ba}, \mathrm{Sr}$ 等)及 $\mathrm{U}$ 等元素在成岩后 发生了一定扰动, 其地化特征也有一定的源区判定 参考意义

\section{2 源区性质}

基性岩样品的可能源区为软流圈地幔或岩石圈 地幔, 由于演化历史和流变学特点的不同二者地球 化学特征差别较大 ${ }^{[45]}$. 岩石圈地幔温度低, 其不存在 地幔对流、不与岩浆发生相互交代作用，因而源于岩 石圈地幔的岩浆普遍具有同位素富集 $\left(\right.$ 高 $\left({ }^{87} \mathrm{Sr} /{ }^{86} \mathrm{Sr}\right)_{\mathrm{i}}$ 值和低 $\varepsilon_{\mathrm{Nd}}$ 值)的特征. 相反, 软流圈地幔温度高, 存在 着低程度熔融体的对流作用，导致源于其中的岩浆 在同位素组成上有着低 $\left({ }^{87} \mathrm{Sr} /{ }^{86} \mathrm{Sr}\right)_{\mathrm{i}}$ 值和高 $\varepsilon_{\mathrm{Nd}}$ 值 ${ }^{[46]}$ 的 亏损特征。

满都拉地区二叠纪基性岩石样品稀土元素整体 丰度较低，在球粒陨石标准化稀土配分模式图上均 呈 LREE 轻度亏损、HREE 轻度富集的向左倾斜的斜 线, 具有与 N-MORB 相似的稀土元素分布特征. 样

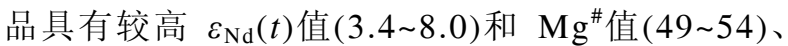
$\mathrm{N}-\mathrm{MORB}$ 型稀土元素分布, 显示了其来源是亏损的 软流圈地幔. 但在 Nd-Sr 同位素初始比值图解(图 8) 中, $\left({ }^{87} \mathrm{Sr} /{ }^{86} \mathrm{Sr}\right)_{\mathrm{i}}$ 值 $(0.70490 \sim 0.70537)$ 高于类似 MORB 源的亏损地幔而与类似 OIB 源的 EM I 型富集地幔 $(0.705)^{[47]}$ 相近, 可能与陆壳物质的加入有关. 地壳的 $\mathrm{La} / \mathrm{Nb}$ 值(2.2) 明显高于原始地幔(0.98 1), 常用来判

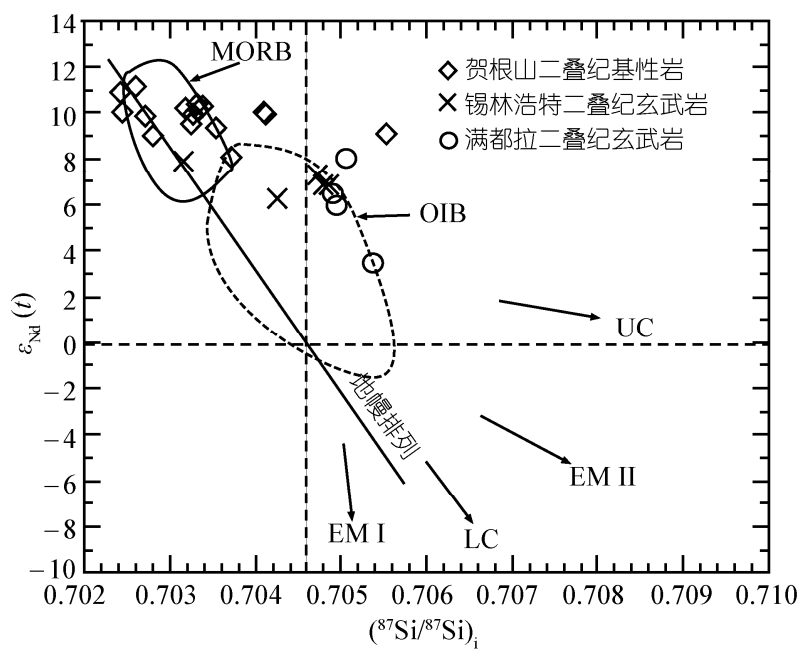

图 8 满都拉玄武岩 Nd-Sr 同位素初始比值图解 贺根山基性岩数据据文献[17]，锡林浩特玄武岩数据据文献[20] 
断地幔物质是否受到陆壳的混染 ${ }^{[47]}$. 满都拉样品的 $\mathrm{La} / \mathrm{Nb}$ 值(2.33 7.29) 明显高于地幔而与地壳值接近, 因此基性岩的源区有陆壳组分的参与. 样品的 ${ }^{206} \mathrm{~Pb} /$ $\left.{ }^{204} \mathrm{~Pb}\right)_{\mathrm{i}}$ 值(17.4 17.9)略低, 在 $\mathrm{Pb}$ 同位素初始比值图解 中落入中国东北新生代玄武岩范围中(图 9), 其源区 被认为是经过交代作用的富集地幔. 基性岩样品普 遍具有低的 $\mathrm{TiO}_{2}$ 含量, 并在原始地幔标准化的微量 元素蛛网图中相对富集 $\mathrm{Rb}, \mathrm{Ba}$ 和 $\mathrm{Sr}$ 等大离子亲石元 素(LILE), $\mathrm{Nb}$ 和 $\mathrm{Ta}$ 具有明显的负异常, 显示了具有 与岛弧火山岩相似的性质, 表明亏损地幔源区可能 受到了俯冲板片的混染和交代作用. 在 $\mathrm{La} / \mathrm{Nb}-\mathrm{La} / \mathrm{Ba}$ 图解(图 10)中, 大部分基性岩样品偏离 OIB 的范围, 可能代表了岩石圈的混染作用和俯冲流体作用对地 幔源区的改造. 样品普遍具有 $\mathrm{Ce}$ 负异常, 说明岩浆 作用过程中海水的参与. 一种可能为基性岩受到了 海水的蚀变作用 (玄武岩受蚀变后可能形成细碧岩); 另一种解释为岩石 $\mathrm{Ce}$ 负异常反映了源区特征, 即岩 浆地幔储库经受了俯冲板片携带的大洋沉积物的改 造. 利用 $\mathrm{LOI}$ 与 $\mathrm{Ce}^{*} / \mathrm{Ce}$ 作图(图略), $\mathrm{Ce}^{*} / \mathrm{Ce}$ 与 $\mathrm{LOI}$ 具 有好的负相关性, 说明基性岩样品发生了热液蚀变. 但镜下观察样品普遍比较新鲜, 说明岩石 $\mathrm{Ce}$ 负异常 还在一定程度上反映了源区较富集的地球化学信息.

此外样品中存在年龄值明显偏大的继承性锆石 (见表 1, 图 3), 且样品同位素组成的变化范围较大 (见表 3), 说明岩浆可能在上升侵位过程中受到了不 同程度的陆壳、弧物质的混染. 由于玄武质岩浆的结 晶分异作用可导致 $\mathrm{SiO}_{2}$ 含量的升高, 但同时 $\mathrm{Th} / \mathrm{La}$
和 $\mathrm{La} / \mathrm{Sm}$ 的增加程度较小; 而地壳物质中 $\mathrm{SiO}_{2}$ 含量、 $\mathrm{Th} / \mathrm{La}$ 和 $\mathrm{La} / \mathrm{Sm}$ 均比原始玄武质岩浆偏高. $\mathrm{SiO}_{2}$ 与 $\mathrm{Th} / \mathrm{La}$ 和 $\mathrm{La} / \mathrm{Sm}$ 均存在较好的相关性(见图 11), 说明 基性岩样品在演化过程中偏离了封闭的岩浆分离结 晶体系, 遭受了一定程度的陆壳物质的混染或岩浆 混合作用.

\section{3 构造意义}

满都拉地区胡吉尔特-查干哈达庙一带的辉长 岩、玄武岩的锆石 SHRIMP U-Pb 年龄分别为 $(278.5 \pm 3.0)$ 和 $(273.7 \pm 1.0)$ Ma. 样品的锆石颗粒结 晶较好, 具有岩浆锆石的特点, 且仅有少数锆石具有 继承性核部, 因此锆石 SHRIMP U-Pb 年龄应该代表 了其岩体的形成年龄. 由于两套岩体样品的形成年 龄相近, 并且在球粒陨石标准化分配图、原始地幔标 准化的微量元素蛛网图上有相似的曲线分布形式, 均显示出两套岩体具有同源的特点, 因此胡吉尔特查干哈达庙一带的基性岩应该形成于同一期岩浆作 用, 岩浆活动时代应为早二叠世.

有关华北北缘二叠纪的构造环境仍存在争议, 一些学者提出二叠纪仍然有洋壳俯冲的记录 ${ }^{[16,20]}$, 一些学者认为在二叠纪古亚洲洋已经闭合, 并进入 造山后伸展扩张的背景 ${ }^{[24,26]}$. 中亚造山带在早二叠 世(295 270 Ma)期间的拉张构造背景下发生了大范 围的高碱性花岗岩的侵位 ${ }^{[51]}$. 华北北缘索伦-贺根山 蛇绿岩带以北广泛发育了早二叠世碱性花岗岩

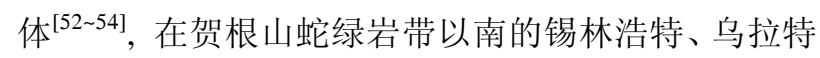
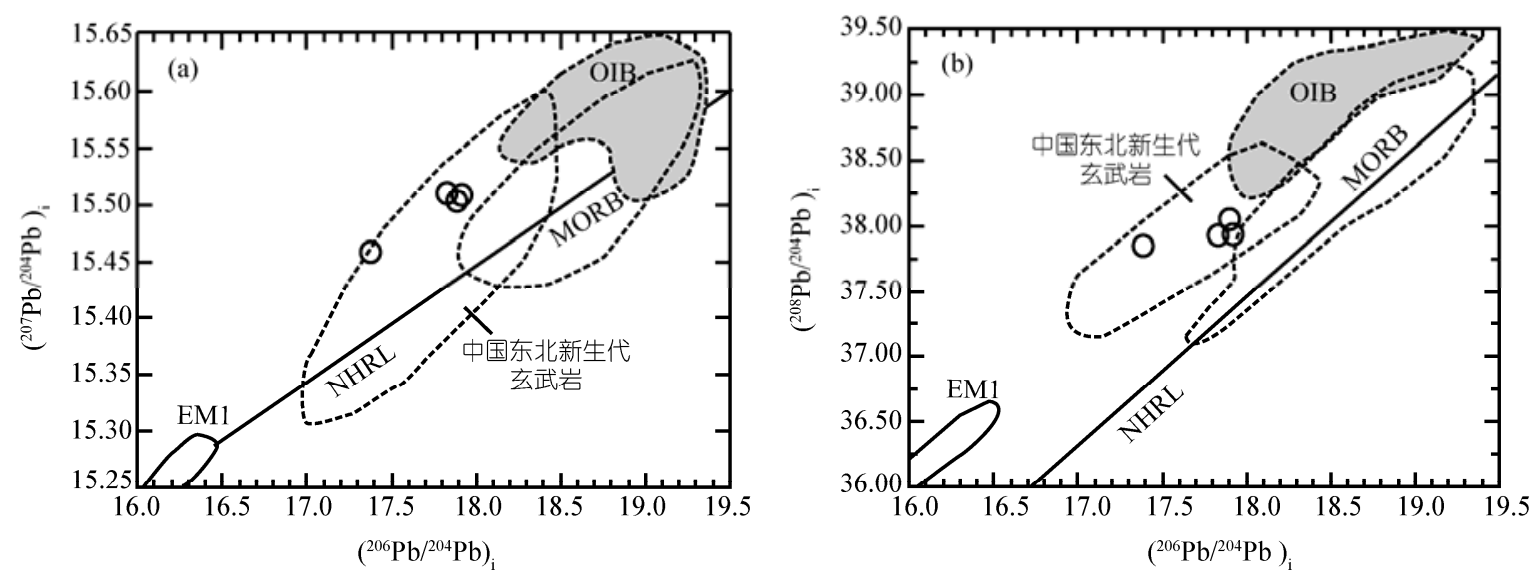

图 9 满都拉玄武岩 $\mathbf{P b}$ 同位素初始比值图解

MORB, OIB 以及 NHRL(北半球参考线) 的范围据文献[48]; 中国东北新生代玄武岩范围据文献[49, 50] 


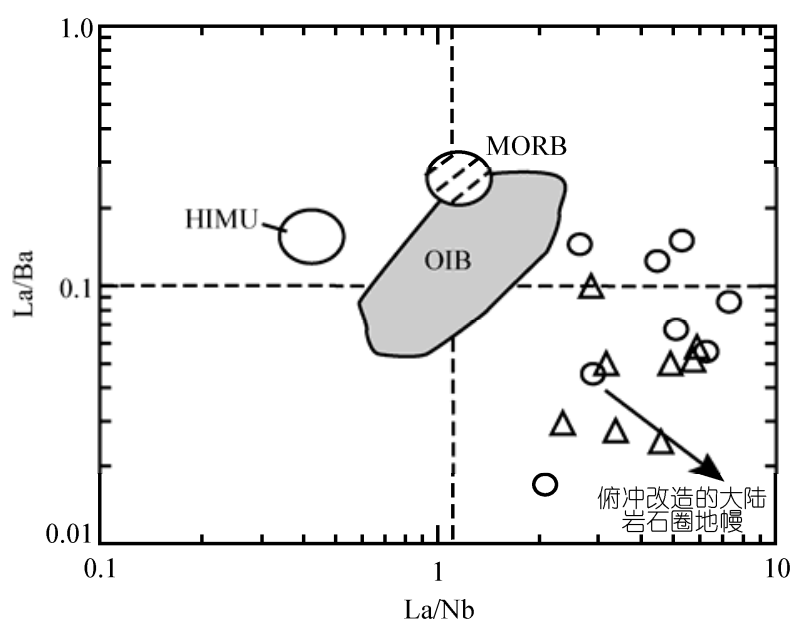

图 $10 \mathrm{La} / \mathrm{Ba}$ 对 $\mathrm{La} / \mathrm{Nb}$ 相关图解

MORB, OIB, HIMU 以及 CLM (大陆岩石圈地幔)的范围据文献[46]

中旗等地也发现了具有 $\mathrm{A}$ 型花岗岩特征的花岗岩 体 ${ }^{[2426] .}$.锡林浩特的基性火山岩与酸性火山岩伴生形 成双峰式火山岩组合, 其 SHRIMP U-Pb 年龄为 $(281 \pm 3) \mathrm{Ma}^{[24]}$, 与本研究区玄武岩的锆石 SHRIMP $\mathrm{U}-\mathrm{Pb}$ 年龄值 $(274 \pm 1) \mathrm{Ma}$ 基本吻合, 两处基性岩均位 于索伦缝合带上, 并且有着较相似的同位素地球化 学特征(见图 8), 因此二者应为同一期构造岩浆作用. 满都拉基性岩中的 REE 及 $\mathrm{Nd}$ 同位素体系受后期扰动 较小, 可用来较可靠的指示其源区特征及构造环境. 样品所具有的 N-MORB 型稀土元素特征及高放射成 因 $\mathrm{Nd}$ 表明, 玄武质岩浆作用与 MORB 有着相似的构 造背景, 即可能形成于强烈的裂谷作用环境.

1997 年内蒙古第一区调队在 1:5 万区域地质调 查时认为胡吉尔特-查干哈达庙一带的火山岩具有蛇 绿混杂堆积性质, 将这套以基性为主的火山岩命名
为胡吉尔特基性火山岩, 同时发现分布在基性火山 岩套中的超基性岩稀土元素总量、分馏特征参数与典 型蛇绿岩完全一致, 被认为是本区的洋壳残片 ${ }^{[31]}$. 据 此, 本研究中满都拉地区的基性岩可能为蛇绿岩套 的组成部分, 其年龄应该代表了本区蛇绿岩的形成 年龄, 说明早二叠世时期本区处于拉张环境下, 形成 了类似于现今红海的有限洋盆. 最近 Miao 等 ${ }^{[20]}$ 对贺 根山蛇绿岩带进行了 SHRIMP U-Pb 精确定年, 得出 岩套中基性岩可靠的年龄值为 295 Ma，与本区基性 岩的锆石年龄相近，同时二者的地球化学特征基本 一致, 在构造位置上分别位于索伦缝合带上和缝合 带北缘，说明两套基性岩应该属于同期且同构造环 境的产物. 贺根山蛇绿岩的出现可能同样指示了满 都拉-贺根山一带在拉伸环境下已形成裂谷, 并经过 进一步发育形成尚未成熟的新洋盆. 因此满都拉基 性岩样品总体具有与 MORB 相似的地球化学特征(高 的 $\left({ }^{143} \mathrm{Nd} /{ }^{144} \mathrm{Nd}\right)_{\mathrm{i}}$ 值、较高的正 $\varepsilon_{\mathrm{Nd}}(t)$ 值、N-MORB 型 稀土元素分布特征), 同时由于洋盆发育不成熟还携 带有与俯冲交代作用有关的富集地幔或者岛弧火山 岩的地球化学信息.

\section{5 结论}

基于满都拉地区晚古生代基性岩的地球化学特 征分析及锆石 SHRIMP U-Pb 精确定年, 得出以下结 论:

(1) 内蒙古达茂旗满都拉地区的辉长岩和玄武 岩岩的锆石 SHRIMP U-Pb 年龄分别为 $(278.5 \pm 3.0)$ 和 $(273.7 \pm 1.0) \mathrm{Ma}$ ，且两套岩石具有同源特点，表明胡 吉尔特-查干哈达庙一带的基性岩应该形成于同一期
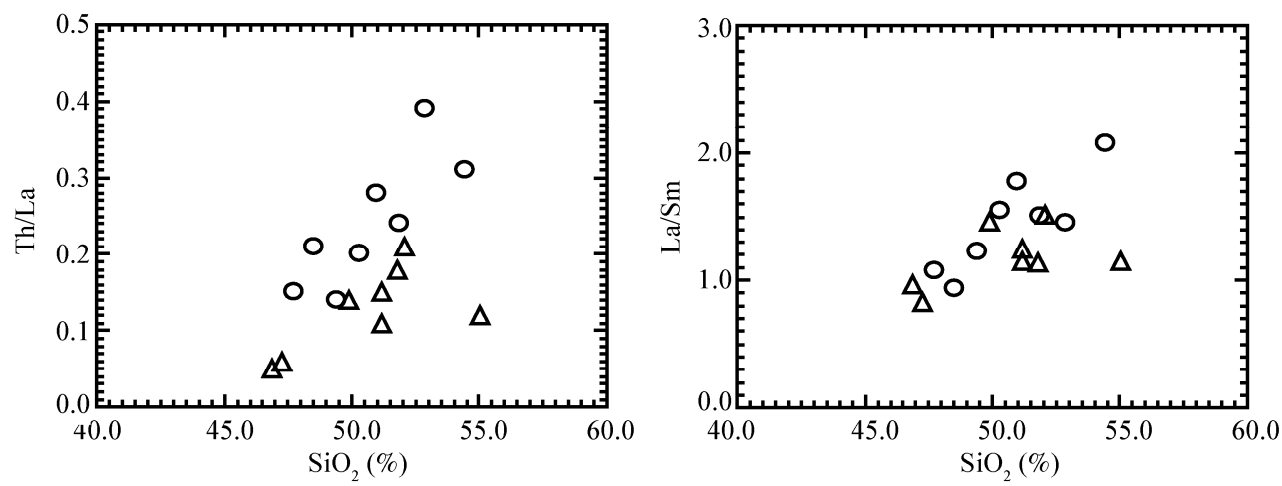

图 $11 \mathrm{Si}_{2} \mathrm{O}-\mathrm{Th} / \mathrm{La}$ 和 $\mathrm{Si}_{2} \mathrm{O}-\mathrm{La} / \mathrm{Sm}$ 相关图解 
岩浆作用, 岩浆活动的时代为早二叠世.

(2) 满都拉地区的二叠纪基性岩具有类似 N-MORB 的 REE 模式特征和高 $\varepsilon_{\mathrm{Nd}}(t)$ 值(3.4 8.0), 显 示其来源是亏损的软流圈地幔; 同时强烈富集 LILE, 亏损 $\mathrm{Nb}-\mathrm{Ta}$ 等 $\mathrm{HFSE}$ 和较高 $\left({ }^{87} \mathrm{Sr} /{ }^{86} \mathrm{Sr}\right)_{\mathrm{i}}$ 值 $(0.70490 \sim$ 0.70537)、较低 $\left({ }^{206} \mathrm{~Pb} /{ }^{204} \mathrm{~Pb}\right)_{\mathrm{i}}$ 值 (17.4 17.9), 反映出 熔融源区可能受到与俯冲消减有关的板片交代和混 染作用; 岩浆在上升侵位过程中经历了陆壳物质的
混染.

(3) 综合研究区样品地球化学特征、前人资料及 对比邻区同期火山岩表明，满都拉地区的二叠纪基 性岩形成于强烈的裂谷作用背景下, 并可能为蛇绿 岩套的组成部分, 其年龄应该代表了本区蛇绿岩侵 位时代. 因此在早二叠世纪时期，满都拉所处的索 伦-贺根山一带在伸展环境下可能存在类似于现今红 海的有限洋盆.

致谢感谢 Nasdala 博士提供实验所需的“锆石标准 M257”, 感谢 Curtin 理工大学的高旻研究员在装载样品、仪器 调试和仪器监控方面所提供的帮助, 还要感谢北京离子探针中心的董春艳博士在远程实验协助和数据处理 方面所提供的帮助. 同时, 感谢韩宝福教授成文过程中的指导与帮助. 匿名审稿专家对论文初稿提出了宝贵 的建设性修改意见，使作者受益匪浅，特此致谢.

\section{参考文献}

1 Sengör A M C, Natal'in B A. Turkin-type orogeny and its role in making of continental crust. Ann Rev Earth Planet Sci, 1996, 24: 263-337

2 Jahn B M, Wu F Y, Chen B. Granitoids of the Central Asian Orogenic Belt and continental growth in the Phanerozoic. Trans R Soc Edinb Earth Sci, 2000, 91: 181-193

3 Kovalenko V I, Yarmolyuk V V, Kovach V P, et al. Isotope provinces, mechanisms of generation and sources of the continental crust in the Central Asian Mobile Belt: Geological and isotopic evidence. J Asian Earth Sci, 2004, 23: 605-627

4 Windley B F, Alexeiev D, Xiao W J, et al. Tectonic models for accretion of the Central Asian Orogenic Belt. Bicentennial Rev J Geol Soc, 2007, 164: 31-47

5 郭锋, 范蔚若, 李超文, 等. 早古生代古亚洲洋俯冲作用: 来自内蒙古大石寨玄武岩的年代学与地球化学证据. 中国科学 $\mathrm{D}$ 辑: 地球 科学, 2009, 39: 569-579

6 Sengör A M C, Natal'in B A. Paleotectonics of Asia: Fragments of a synthesis. In: Yin A, Harrison T M, eds. The Tectonic Evolution of Asia. Cambridge: Cambridge University Press, 1996. 486-641

7 Tang K D. Tectonic development of Paleozoic foldbelts at the northern margin of the Sino-Korean Craton. Tectonics, 1990, 9: 249-260

8 邵济安. 中朝板块北缘中段地壳演化. 北京: 北京大学出版社, 1991. 136

9 唐克东. 中朝板块北侧禇皱带构造演化及成矿规律. 北京: 北京大学出版社, 1992

10 Xiao W J, Windley B C, Huang C M, et al. End-Permian to mid-Triassic termination of the accretionary processes of the southern Altaids: Implications for the geodynamic evolution, Phanerozoic continental growth, and metallogeny of central Asia. Int J Earth Sci (Geol Rundsch), 2009, 98: 1189-1217

11 Xiao W J, Windley B F, Hao J, et al. Accretion leading to collision and the Permian Solonker suture, Inner Mongolia, China: Termination of the Central Asian Orogenic Belt. Tectonics, 2003, 22: 1069-1088

12 Li J Y. Permian geodynamic setting of Northeast China and adjacent regions: Closure of the Paleo-Asian Ocean and subduction of the Paleo-Pacific Plate. J Asian Earth Sci, 2006, 26: 207-224

13 陈斌, 马星华, 刘安坤, 等. 锡林浩特杂岩和蓝片岩的锆石 U-Pb 年代学及其对索伦缝合带演化的意义. 岩石学报, 2009, 25: 3123-3129

14 Chen B, Jahn B M, Tian W. Evolution of the Solonker suture zone: Constraints from zircon U-Pb ages, Hf isotopic rations and whole-rock Nd-Sr isotopic compositions of subductions- and collision-related magmas and forearc sediments. J Asian Earth Sci, 2009, 34: 245-257

15 Chen B, Jahn B M. Genesis of post-collisional granitoids and basement nature of the Junggar Terrane, NW China: Nd-Sr isotope and trace element evidence. J Asian Earth Sci, 2004, 23: 691-704

16 Chen B, Jahn B M, Wilde S, et al. Two contrasting paleozoic magmatic belts in northern Inner Mongolia, China: Petrogenesis and tectonic implications. Tectonophysics, 2000, 328: 157-182

17 Wu F Y, Zhao G C, Sun D Y, et al. The Hulan Group: its role in the evolution of the Central Asian Orogenic Belt of NE China. J Asian Earth Sci, 2007, 30: 542-556 
18 尚庆华. 北方造山带内蒙古中、东部地区二叠纪放射虫的发现及意义. 科学通报, 2004, 49: 2574-2579

19 Zhang S H, Zhao Y, Song B, et al. Carboniferous granitic plutons from the northern margin of the North China block: Implications for a late Paleozoic active continental margin. J Geol Soc Lond, 2007, 164: 451-463

20 Miao L C, Fan W M, Liu D Y, et al. Geochronology and geochemistry of the Hegenshan ophiolitic complex: Implications for late-stage tectonic evolution of the Inner Mongolia-Daxinganling Orogenic Belt, China. J Asian Earth Sci, 2008, 32: 348-370

21 Deng S H, Wan C B, Yang J G. Discovery of a Late Permian Angara-Cathaysia mixed flora from Acheng of Heilongjiang, China, with discussions on the closure of the Paleoasian Ocean. Sci China Ser D-Earth Sci, 2009, 52: 1746-1755

22 包志伟, 陈森煌, 张桢堂. 内蒙古贺根山地区蛇绿岩稀土元素和 Sm-Nd 同位素研究. 地球化学, 1994, 23: 339-348

23 洪大卫, 黄怀曾, 肖宜君, 等. 内蒙古中部二叠纪碱性花岗岩及其地球动力学意义. 地质学报, 1994, 68: 217-230

24 Zhang X H, Zhang H F, Tang Y J, et al. Geochemistry of Permian bimodal volcanic rocks from central Inner Mongolia, North China: Implication for tectonic setting and Phanerozoic continental growth in Central Asian Orogenic Belt. Chem Geol, 2008, 249: 262-281

25 Shi G H, Miao L C, Zhang F Q, et al. Emplacement age and tectonic implications of the Xilinhot A-type granites in Inner Mongolia, China. Chin Sci Bull, 2004, 49: 723-729

26 罗红玲, 吴泰然, 赵否. 华北板块北缘乌梁斯太 A 型花岗岩体锆石 SHRIMP U-Pb 定年及构造意义. 岩石学报, 2009, 25: 515-526

27 周志广, 谷永昌, 柳长峰, 等. 内蒙古东乌珠穆沁旗满都胡宝拉格地区早-中二叠世华夏植物群的发现及地质意义. 地质通报, 2010 , 29: $21-25$

28 徐备, 陈斌. 内蒙古北部华北板块与西伯利亚板块之间中古生代造山带的结构及演化. 中国科学 D 辑: 地球科学, 1997, 27: 227-232

29 Luo H L, Wu T R, Zhao L. Permian high Ba-Sr granitoids: Geochemistry, age and tectonic implications of Erlangshan pluton, Urad Zhongqi, Inner Mongolia. Acta Geol Sin, 2009, 83: 603-614

30 陶继雄, 白立冰, 宝音乌力吉, 等. 内蒙古满都拉地区二叠纪俯冲造山过程的岩石记录. 地质调查与研究, 2003, 26: 241-249

31 苏新旭, 孟二根, 张永清. 内蒙古达茂旗满都拉地区晚古生代板块活动探讨. 内蒙古地质, 2000, 1: 17-34

32 王惠, 王玉净, 陈志勇, 等. 内蒙古巴彦敖包二叠纪放射虫化石的发现. 地层学杂志, 2005, 29: 368-372

33 Jian P, Liu D Y, Kröner A, et al. Time scale of an early to mid-Paleozoic orogenic cycle of the long-lived Central Asian Orogenic Belt, Inner Mongolia of China: Implications for continental growth. Lithos, 2008, 101: 233-259

34 Compston W, Williams I S, Kirschvink J L, et al. Zircon U-Pb ages for the Early Cambrian time-scale. J Geol Soc Lond, 1992, 149: $171-184$

35 宋彪, 张玉海, 万渝生, 等. 锆石 SHRIMP 样品靶制作、年龄测定及有关现象讨论. 地质评论, 2002, 48(增刊): 26-30

36 Nasdala L, Hofmeister W, Norberg N, et al. Zircon M257-a homogeneous natural reference material for the ion microprobe U-Pb analysis of zircon. Geostand Geoanaly Res, 2008, 32: 247-265

37 Ludwig K R. Isoplo 3.0-A Geochronological Toolkit for Microsoft Excel. Berkeley Geochronol Center Spec Publ, 2003, 4: 1-70

38 Steiger R H, Jager E. Subcommission on geochronology: Convention on the use of decay constants in geo- and cosmochronology. Earth Planet Sci Lett, 1977, 36: 359-362

39 Cox K G, Bell J D, Pankhurst R J. The Interpretation of Igneous Rocks. London: Allen and Unwin, 1979

40 Wilson M. Igneous Petrogenesis. London: Allen and Unwin, 1989

41 Irvine A J, Baragar W R A. A guide to the chemical classification of the common volcanic rocks. Canad J Earth Science, 1971, 8: 512-548

42 Sun S S, McDonough W E. Chemical and isotopic systematic of oceanic basalts: Implications for mantle composition and processes. In: Saunders A D, Norry M J, eds. Magmatism in the Ocean Basins. Geol Soc Lond Spec Publ, 1989, 42: 313-345

43 Gibson S A, Kirkpatrick R J, Emmermann R, et al. The trace element composition of lavas and dykes from a $3 \mathrm{~km}$ vertical section through a lava pile in Eastern Iceland. J Geophys Res, 1982, 87: 6532-6546

44 Pearce J A, Thirlwall M F, Ingram G, et al. Isotopic evidence for the origin of Boninites and related rocks drilled in the Izu-Bonin (Ogasawara) forearc, Leg 125. In: Fryer P, Pearce J A, Stokking L, et al, eds. Proc Ocean Drilling Program Scient Results, 1992, 125: 237-261

45 Zhang H F, Sun M, Zhou X H, et al. Geochemical constraints on the origin of Mesozoic alkaline intrusive complexes from the North China Craton and tectonic implications. Lithos, 2005, 81: 297-317

46 Saunders A D, Storey M, Kent R W, et al. Consequences of plume-Lithosphere interactions. In: Storey B C, Alabaster T, Pankhurst R J, eds. Magmatism and the Cause of Continental Breakup. Geol Soc Lond Spec Publ, 1992, 68: 41-60

47 Dungan M A, Lindstrom M M, Mcmiland N J, et al. Open system magmatic evolution of the Taos Plateau volcanic field, northern New Mexico, the petrology and geochemistry of the Servillets basalt. J Geophys Res, 1986, 91: 5999-6028

48 Zindler A, Hart S R. Chemical geodynamics. Annual Rev Earth Planet Sci, 1986, 14: 493-571 
49 Liu C Q, Masuda A, Xie G H. Major and trace element compositions of Cenozoic basalts in eastern China: Petrogenesis and mantle source. Chem Geol, 1994, 111: 19-42

50 Zou H B, Zindler A, Xu X S. Major, trace element, and Nd, Sr and Pb studies of Cenozoic basalts in SE China: Mantle sources, regional variations and tectonic significance. Chem Geol, 2000, 171: 33-47

51 Jahn B M, Litvinovsky B A, Zanvilevich A N, et al. Peralkaline granitoid magmatism in the Mongolian-Transbaikalian Belt: Evolution, petrogenesis and tectonic significance. Lithos, 2009, 113: 521-539

52 Hong D W, Wang S G, Han B F, et al. Post-orogenic alkaline granites from China and comparisons with anorogenic alkaline granites elsewhere. J Southeast Asian Earth Sci, 1996, 13: 13-27

53 Kovalenko V I, Yarmoluyk V V, Kozlovsky A M, et al. Two types of magma sources of rare-metal alkali granites. Geol Ore Deposit, 2007, 49: 442-446

54 Kovalenko V I, Yarmoluyk V V, Sal'nikova E B, et al. Geology, geochronology and geodynamics of the Khan Bogd alkali granites pluton in southern Mongolia. Geotectonics, 2006, 40: 450-466 